Hydrol. Earth Syst. Sci. Discuss., doi:10.5194/hess-2016-557, 2016

Manuscript under review for journal Hydrol. Earth Syst. Sci.

Published: 1 November 2016

(c) Author(s) 2016. CC-BY 3.0 License.

\title{
High-Resolution Virtual Catchment Simulations of the Subsurface- Land Surface-Atmosphere System
}

Bernd Schalge $^{1}$, Jehan Rihani ${ }^{2}$, Gabriele Baroni ${ }^{3,4}$, Daniel Erdal ${ }^{5}$, Gernot Geppert ${ }^{6}$, Vincent Haefliger ${ }^{1}$, Barbara Haese $^{7}$, Pablo Saavedra ${ }^{1}$, Insa Neuweiler ${ }^{8}$, Harrie-Jan Hendricks Franssen ${ }^{9,11}$, Felix Ament ${ }^{6}$, 5 Sabine Attinger ${ }^{3}$, Olaf A. Cirpka ${ }^{5}$, Stefan Kollet ${ }^{9,11}$, Harald Kunstmann ${ }^{7,10}$, Harry Vereecken ${ }^{9,11}$, Clemens Simmer ${ }^{1}$

${ }^{1}$ University of Bonn, Meteorological Insititute, Bonn, Germany

${ }^{2}$ University of Cologne, Mathematical Institute, Cologne, Germany

${ }^{3}$ Helmholtz-Center for Environmental Research, Leipzig, Germany

$10{ }^{4}$ University of Potsdam, Institute of Earth and Envirenmental Science, Potsdam, Germany

${ }^{5}$ University of Tuebingen, Center for Applied Geoscience, Tuebingen, Germany

${ }^{6}$ University of Hamburg, Meteorological Insititute, Hamburg, Germany

${ }^{7}$ University of Augsburg, Institut fuer Geographie, Augsburg, Germany

${ }^{8}$ Leibniz University Hannover, Institut fuer Stroemungsmechanik und Umweltphysik im Bauwesen, Hannover, Germany

$15 \quad{ }^{9}$ Forschungszentrum Juelich GmbH, Agrosphere (IBG-3), Juelich, Germany

${ }^{10}$ Karlsruhe Institute of Technology (KIT), Institute of Meteorology and Climate Research (IMK-IFU), GarmishPartenkirchen, Germany

${ }^{11}$ Centre for High-Performance Scientific Computing (HPSC-TerrSys), Geoverbund ABC/J, Juelich, Germany

Correspondence to: Bernd Schalge(bschalge @uni-bonn.de)

20 Abstract. Combining numerical models, which simulate water and energy fluxes in the subsurface-land surface-atmosphere system in a physically consistent way, becomes increasingly important to understand and study fluxes at compartmental boundaries and interdependencies of states across these boundaries. Complete state evolutions generated by such models, when run at highest possible resolutions while incorporating as many processes as attainable, may be regarded as a proxy of the real world - a virtual reality - which can be used to test hypotheses on functioning of the coupled terrestrial system and may serve as source for virtual measurements to develop data-assimilation methods. Such simulation systems, however, face severe problems caused by the vastly different scales of the processes acting in the compartments of the terrestrial system. The present study is motivated by the development of cross-compartmental data-assimilation methods, which face the difficulty of data scarcity in the subsurface when applied to real data. With appropriate and realistic measurement operators, the virtual reality not only allows taking virtual observations in any part of the terrestrial system at any density, thus overcoming data-scarcity problems of real-world applications, but also provides full information about true states and parameters aimed to be reconstructed from the measurements by data assimilation. In the present study, we have used the Terrestrial Systems Modeling Platform TerrSysMP, which couples the meteorological model COSMO, the land-surface model CLM, and the subsurface model ParFlow, to set up the virtual reality for a regional terrestrial system roughly oriented at the Neckar catchment in southwest Germany. We find that the virtual reality is in many aspects quite close to real observations of the catchment concerning, e.g., atmospheric boundary-layer height, precipitation, and runoff. But also discrepancies become apparent both 
Hydrol. Earth Syst. Sci. Discuss., doi:10.5194/hess-2016-557, 2016

Manuscript under review for journal Hydrol. Earth Syst. Sci.

Published: 1 November 2016

(c) Author(s) 2016. CC-BY 3.0 License.

in the ability of such models to correctly simulate some processes - which still need improvement - and the realism of the results of some observation operators like the SMOS and SMAP sensors, when faced with model states. In a succeeding step, we will use the virtual reality to generate observations in all compartments of the system for coupled data assimilation. The data assimilation will rely on a coarsened and simplified version of the model system.

\section{Introduction}

Numerical models, which simulate water and energy fluxes in the subsurface-land surface-atmosphere system in a physically consistent way, are important ingredients to climate and weather prediction, flood forecasting, water resources management, agriculture, and water quality control (Shrestha et al. 2014; Larsen et al. 2014; Simmer et al., 2015). Recent developments embrace the combination of coupled land surface-subsurface models with data assimilation (DA) techniques in order to obtain

10 real-time forecasts of the development of the coupled system (Shi et al., 2014, 2015; Ridler et al., 2014; Kurtz et al., 2016). Different data assimilation philosophies and methods exist encompassing nudging, variational and sequential ensemble-based methods (e.g. Kalnay 2003). Yet the development and choice of appropriate data assimilation methods is limited by the availability of observational information across all compartments as well as by appropriately characterized real-world systems. The use of virtual reality (VR) systems that provide a virtual truth and deliver full information about the subsurface-land surface-atmosphere system can be key for the development of a consistent data assimilation framework.

Virtual realities have already been used for specific compartments of the coupled terrestrial system (see Fatichi et al., 2016 and reference herein). Bashford et al. (2002) computed virtual remote-sensing observations with $1 \mathrm{~km}$ resolution to derive, among others, process parameterizations for evapotranspiration in a hydrological model operating on the same scale as the remote sensing data. Weiler and McDonnel (2004) used a virtual-reality approach on the hill-slope scale to detect and quantify

20 the major controls on subsurface flow processes and derive tunable parameters for conceptual models. Virtual experiments were defined by Schlueter et al. (2012) to explore the relationship between soil architecture and hydraulic behavior and by Chaney et al. (2015) for testing sampling designs. In groundwater hydrology it is a standard procedure to test inverse modeling and data assimilation approaches on virtual computational aquifers (e.g., Zimmermann et al., 1998; Hendricks Franssen et al., 2009). These are used to generate realistic data of an aquifer with exactly known hydraulic and geochemical properties at every

25 point (e.g., Schaefer et al. 2002). More recently also integrated modeling approaches were considered to generate virtual realities (Mackay et al., 2015).

The application of the virtual-reality concept for developing data-assimilation systems has the following main advantages:

(I) For the prediction of fluxes and states in a real-world subsurface-land surface-atmosphere system, we do not know whether the errors in our predictions are due to incomplete model specification (model structural errors), wrong 30 parameterizations, erroneous model parameters, measurement errors, or defects in data assimilation. Working with a virtual truth allows separating model structural error both in the coupled terrestrial model and in the measurement operators from the 
Hydrol. Earth Syst. Sci. Discuss., doi:10.5194/hess-2016-557, 2016

proper data-assimilation problems, like the generation of the ensemble or the choice of the filters. Working only with realworld data would hardly allow the attribution of prediction errors to their causative sources.

(II) The immense scale complexity of terrestrial systems renders already the estimation of its state often very challenging despite the wealth of observations available nowadays from in-situ and remote sensing. Available measurements never cover

5 all locations and times, thus only parts of the heterogeneities can be probed. Moreover, any measurement technology sees only a certain part of reality. It is not always clear whether observations contain enough information with the appropriate spatial and temporal resolution to substantially improve predictions. With the virtual reality we may circumvent data scarcity in dataassimilation problems. In real-world applications, there are never enough observations available to define a "truth" against which data-assimilation methods can be tested. The virtual-reality approach allows generating arbitrarily long time series and

10 high-density observations to work with, and it facilitates comparing estimated states and parameters to the truth everywhere at all times. This is especially true for coupled subsurface-land surface-atmosphere problems, for which data assimilation has not been evaluated and tested until now.

(III) Studies on data assimilation using different observation densities, observation errors, and data types will provide insight into data value and thus contribute to the development of better monitoring designs for improved predictions of states 15 and fluxes.

(IV) Virtual realities are a unique testbed to develop and validate data-assimilation methods as well as the impact of the underlying assumptions (e.g., Gaussianity). In particular, weakly and fully coupled data assimilation can be compared. In weakly coupled data assimilation, sequential data assimilation is done for multiple compartments of the terrestrial system (e.g., groundwater, land surface and atmosphere), but observations made for a given compartment only update states (and possibly

20 parameters) within that compartment and not in other compartments. In fully coupled data assimilation, by contrast, observations are available for multiple compartments of the terrestrial system and are used to update states (and possibly parameters) across different compartments of the terrestrial system through cross-correlations, which may be inferred from ensemble statistics of the fully coupled system.

(V) Finally, virtual realities allow examining the effects of conceptual assumptions regarding process descriptions of

25 various degrees of complexity, spatial resolution of heterogeneities, and representation of boundary conditions, among others, on overall system behavior.

In this paper we present the development and testing of a catchment-based virtual-reality system as a first step in the development of a weakly or strongly coupled data-assimilation system; such systems allow for the assimilation of all observation types made in all compartments of the subsurface-land surface-atmosphere system at the same time. Our virtual

30 reality represents the fully coupled terrestrial system from the bedrock to the upper atmosphere covering the catchment of a higher-order river (length $\approx 380 \mathrm{~km}$, area $\approx 14000 \mathrm{~km}^{2}$ ) with a buffer zone surrounding it, in which we simulate - as realistically as possible - the evolution of states in all compartments and the water and energy fluxes throughout the system. This virtual reality provides a virtual truth, from which arbitrary (virtual) observations can be made and which avoids the lack of information for a thorough evaluation of data-assimilation systems. Towards this ends, the model of the subsurface-land 
Hydrol. Earth Syst. Sci. Discuss., doi:10.5194/hess-2016-557, 2016

surface-atmosphere system needs to represent the strong spatial variability especially of the land component, which affect the overall system behavior due to nonlinear couplings and feedbacks.

Setting up and executing a fully coupled virtual reality comes with challenges. Without a sufficiently detailed representation of the relations and dependencies of fluxes, states, and parameters in different compartments, the applicability of any data-

5 assimilation method derived from the setup of the virtual reality will be questionable. Since - for a chosen size of the catchment - IT-requirements limit the spatial resolution of the fully coupled model, a balance needs to be found between the detail in process representation and computational feasibility. Accordingly, for some processes appropriate upscaling rules or apparent parameters need to be introduced and applied in order to guarantee that the interrelations between different observations and forcings are adequately represented. Here we report on first steps to derive the virtual reality for a catchment and discuss in

10 particular the limitations.

Since a virtual reality with no resemblance to a real world catchment hardly allows for evaluating its realism, we base our virtual reality loosely on the Neckar catchment in southwest Germany, that contains variable topography, different land cover, high and low precipitation regions, deep and low water tables, regions prone to flooding events etc. (see Figure 1). The model does not aim at exactly reproducing the catchment's response to hydro-climatic forcing, instead we only require that the

15 simulated response is realistic with respect to typical spatial and temporal characteristics. The model needs to simulate realistic responses in all state variables forming the basis for typical measurements eventually produced by measurement (forward) operators. This requires that the virtual reality is run at very high resolution. Thus, the main objective of this paper is to explain how we created the virtual reality and prove the realism of the generated data and observations.

The remainder of the paper is structured as follows. In section 2, we introduce the simulation platform TerrSysMP, while

20 Section 3 describes in detail the surface and subsurface parameters for topography, soil, land use, vegetation, and the river network. In Section 4, we show some snapshots and time series of state variables or system parameters extracted from the virtual reality. In Section 5, we compare virtual observations obtained from the virtual reality with real observations to demonstrate how the most important requirements for the virtual reality are met. These results are discussed in Section 6 together with several issues, which came up when developing the virtual reality. We provide conclusions and an outlook in

25 Section 7.

\section{The Terrestrial Systems Modeling Platform (TerrSysMP)}

We used the Terrestrial System Modeling Platform (TerrSysMP, see Shrestha et al. 2014; Gasper et al. 2014; Sulis et al. 2015) developed within the Transregional Collaborative Research Centre TR32 (see Simmer et al. 2015) for the generation of the virtual reality (VR). TerrSysMP couples (Figure 2) the hydrologic flow model ParFlow v693 (Ashby and Falgout, 1996; Jones

30 and Woodward, 2001; Kollet and Maxwell, 2006), the Community Land Model, CLM v3.5 (Oleson et al, 2008), and the Consortium for Small Scale Modeling (COSMO v4.21) model (Baldauf et al. 2011) via the Ocean Atmosphere Sea Ice 
Hydrol. Earth Syst. Sci. Discuss., doi:10.5194/hess-2016-557, 2016

Manuscript under review for journal Hydrol. Earth Syst. Sci.

Published: 1 November 2016

(c) Author(s) 2016. CC-BY 3.0 License.

Coupling framework OASIS3 (e.g. Valcke et al., 2006), using a dynamical two-way approach including down- and upscaling algorithms for fluxes and state variables between computational grids of different resolution.

ParFlow is a variably saturated watershed flow model which solves the three-dimensional Richard's equation to model saturated and unsaturated flow in the subsurface, and the fully integrated kinematic wave equation to model two-dimensional overland flow. Other global and regional hydrological models use this equation to route overland flow, being already tested in the MODCOU model (Haefliger et al. 2015) and currently used in the TRIP model (Alkama et al. 2012). Advanced NewtonKrylov multigrid solvers are used, that are especially suitable for massively parallel computer environments. Excellent model performance and parallel efficiency have been documented by Jones and Woodward (2001), Kollet and Maxwell (2006), and Kollet et al. (2010). A unique feature of ParFlow is the use of an advanced octree data structure for rendering overlapping 10 objects in 3-D space, which facilitates modeling of complex geology and heterogeneity as well as the representation of topography based on digital elevation models and watershed boundaries.

CLM is a single column biogeophysical land-surface model considering coupled snow-, soil-, and vegetation-processes. CLM is released by the National Center for Atmospheric Research (NCAR). Land surface heterogeneity is represented as a nested subgrid hierarchy in which grid cells are composed of multiple land units (glacier, lake, wetland, urban, and vegetation),

15 snow/soil columns (to capture variability in snow and soil state variables within each land unit), and Plant Functional Types (PFTs) to capture the biogeophysical and biogeochemical differences between broad categories of plants in terms of their functional characteristics. In TerrSysMP, the 1-D Richards-equation model included in CLM is replaced by ParFlow.

COSMO is a limited-area, non-hydrostatic numerical weather prediction model, which operationally runs at the German weather service DWD, among others, for Numerical Weather Prediction (NWP) and various scientific applications on the

20 meso- $\beta$ and meso- $\gamma$ scale. COSMO is based on the primitive thermo-hydrodynamical equations describing compressible flow in a moist atmosphere. As a limited-area model, COSMO needs lateral boundary conditions from a driving larger-scale model. We impose the lateral conditions by nesting COSMO into COSMO-EU which spans all of Europe, or in COSMO-DE which spans Germany. The lateral boundary formulation used is a relaxation technique in which the internal model solution is nudged against an externally specified solution over a narrow transition zone between the two domains.

25 Within OASIS3, the upscaling algorithm uses the mosaic or explicit sub-grid approach (Avissar and Pielke 1989) in which high-resolution land surface fluxes are averaged to be transferred to the coarser resolution of the atmospheric model component. The implemented Schomburg scheme (Schomburg et al., 2010, 2012) downscales atmospheric variables of the lowest atmospheric model layer to the higher-resolved land surface model. The scheme involves (i) spline interpolation while conserving mean and lateral gradients of the coarse field, (ii) deterministic downscaling rules to exploit empirical relationships

30 between atmospheric variables and surface variables, and (iii) the addition of high-resolution variability (i.e. noise) in order to restore spatial variability. The scheme has been developed and tested for downscaling $2.8 \mathrm{~km}$ atmospheric simulations by COSMO to $400 \mathrm{~m}$ for the land surface.

TerrSysMP allows simulating the terrestrial water, energy, and biogeochemical cycles from the deeper subsurface including groundwater (ParFlow) across the land-surface (CLM) into the atmosphere (COSMO). Water and energy cycles are coupled 
Hydrol. Earth Syst. Sci. Discuss., doi:10.5194/hess-2016-557, 2016

Manuscript under review for journal Hydrol. Earth Syst. Sci.

Published: 1 November 2016

via evaporation and plant transpiration; these processes are modeled by CLM with a non-linear coupling to ParFlow through soil-water availability and root-water uptake (Figure 2). The two-way coupling between CLM and COSMO encompasses radiation exchange and turbulent exchanges of moisture, energy, and momentum. OASIS3 allows different temporal and spatial resolutions of the coupled model components. For example, a temporal resolution of 15 minutes is sufficient for the

5 subsurface and land-surface components, whereas time steps as small as 5 seconds are needed for the atmosphere. A higher spatial resolution can be assigned for the surface and subsurface parts to allow for a better representation of soil and land-use heterogeneity. Each model component can also be used standalone; coupled runs of ParFlow and CLM using atmospheric inputs from offline driven COSMO simulations or other sources are as well possible as COSMO runs coupled with CLM without ParFlow, and thus without 3-D soil and groundwater dynamics.

\section{Description of the Virtual Reality}

Our virtual reality is based on the Neckar catchment in the south-west German state of Baden-Wuerttemberg (see Figure 1), east of the mountain range of the Black Forest and north of the Jurassic ridge of the Swabian Alb. Some features that are characteristic for the domain, such as middle Triassic and Jurassic karst aquifers, are not included to avoid the manifold hydrological challenges related to its modeling. The catchment has a varying topography including mountains up to $1050 \mathrm{~m}$

15 a.s.l., river valleys, different land use types, i.e. grassland, cropland (majority of the area), broadleaf and needle leaf forest (see Figure 3), and soil classes. The computational domain of the virtual reality is larger than the Neckar catchment to allow the atmospheric model to develop its own internal dynamics.

Annual mean precipitation over the real catchment ranges between 600 and 2000mm (see Section 3.1) with highest values over the Black Forest. Inter-annual variability of precipitation can deviate by up to one third of the mean value. Monthly

20 precipitation can vary largely and its mean annual cycle is weak with slightly lower values in spring and autumn. While summer precipitation is dominated by convection, winter precipitation is predominantly related to fronts of extra-tropical cyclones with enhanced precipitation over the mountains due to orographic lift. Daily average temperatures vary with altitude between $-5^{\circ} \mathrm{C}$ and $0^{\circ} \mathrm{C}$ in January and 13 and $18^{\circ} \mathrm{C}$ in July. Land use and cover in the lower elevations are dominated by agriculture while the Black Forest features mainly needle-leaf trees. Broad-leaf trees can be found over smaller areas throughout the catchment.

25 Distance to groundwater is in large parts of the area restricted to a few meters, which assures strong coupling between groundwater depth and evapotranspiration.

The described features are quite typical for central Europe, which led us to choose the Neckar catchment as the location of the virtual reality. We use two realizations with different spatial extensions, spatial resolutions and coupling degrees as intermediate steps towards a fully coupled system. Domain 1 covers the entire area at a somewhat coarser resolution, whereas

30 the more finely resolved Domain 2 is restricted to the upper Neckar catchment, defined by the gaging station Plochingen. This two-step approach better allows experimenting with the model and evaluating its realism. In addition, there is currently a software restriction, which does not allow for cases with more than 4.2 million CLM columns; thus currently the high resolution 
Hydrol. Earth Syst. Sci. Discuss., doi:10.5194/hess-2016-557, 2016

Manuscript under review for journal Hydrol. Earth Syst. Sci.

Published: 1 November 2016

(c) Author(s) 2016. CC-BY 3.0 License.

of Domain 2 cannot be used for the full Neckar catchment area of Domain 1. Domain 1 is a rectangular area of $\sim 57,850 \mathrm{~km}^{2}$ which encompasses the whole Neckar catchment of $\sim 14,000 \mathrm{~km}^{2}$. Coupling is restricted to COSMO and CLM, i.e. the 3-D groundwater flow representation by ParFlow is deactivated and the spatial resolution is reduced compared to Domain 2. The latter covers only the upper Neckar catchment $\left(2,621 \mathrm{~km}^{2}\right)$ and restricts coupling to CLM and ParFlow with COSMO output

5 used as atmospheric forcing (Figure 1).

\subsection{Domain 1: Entire Neckar Catchment with Bounding Areas}

In Domain 1, both COSMO and CLM run at the same horizontal resolution of $\sim 1.1 \mathrm{~km}\left(0.01^{\circ}\right.$ in rotated COSMO latitudelongitude coordinates). Due to projections between real (CLM) and rotated (COSMO) geographical coordinates, misplacements of land surface pixels in CLM in relation to their original locations can be up to half a grid diameter.

10 COSMO is set up identical to the operational COSMO-DE setup of the German Weather Service DWD, e.g., the deep convection parameterization is switched off because at the chosen grid resolution convection is enabled by the dynamical core (see Section 2.1). In COSMO-DE, the operational solution is $2.8 \mathrm{~km}$, so that the approximation regarding deep convection is even more appropriate in our virtual reality. Similar choices were taken by Smith et al. (2015), who simulated precipitation events of roughly the same domain using nested WRF models, where cumulus parameterization was switched off at horizontal

15 resolutions of $900 \mathrm{~m}$ and $300 \mathrm{~m}$. Lateral boundary forcing and constant fields (topography, land-mask etc.) are provided by the COSMO-DE analysis fields, which are downscaled to the $1.1 \mathrm{~km}$ grid by linear interpolation. The lateral relaxation zone, which moderates the jump from the lateral driving fields to the inner model area, is set to $12 \mathrm{~km}$.

For setting up CLM, the European digital elevation model (DEM) by the European Environment Agency EEA (http://www.eea.europa.eu/data-and-maps/data/eu-dem) was projected to the latitude/longitude grid and bi-linearly

20 interpolated to $1.1 \mathrm{~km}$ from the original 30m spatial resolution. Land use is taken from the 2006 Corine Land Cover Data Set (http://www.eea.europa.eu/data-and-maps/data/corine-land-cover-2006-raster-3) and also provided by EEA. Since the latter dataset features many more land use types (at a resolution of 100m) than required by CLM, they were grouped according to the CLM (IGBP) Plant Functional Type classes (1) broad-leaf forests, (2) needle-leaf forests, (3) grassland, (4) cropland, and (5) bare soil. Urban areas are not considered in our virtual reality and replaced by bare soil. Water surfaces (e.g., larger lakes

25 like Lake Constance in the South of Domain 1) are also treated as (always fully saturated) bare-soil in CLM while COSMO uses its own land-mask and specific calculations for water surfaces. Therefore, no values from CLM are used for water surfaces. A few hundred grid cells feature shrubs (mostly areas that are re- or de-forested or areas at higher altitudes) which are treated as forests, and each grid cell features only one - the most dominant - plant functional type. The plant Leaf Area Index (LAI) is computed from MODIS (Myneni et al. 2002) as monthly averages for the year 2008 for each of the four

30 vegetated land use classes. This LAI is increased for all plant functional types by about 20 percent in the summer months and significantly changed from factors less than 1 to about 3.3 in winter-time for needle-leaf forests in order to account for known biases in the MODIS data (Tian et al. 2004). The stem area index (SAI) is estimated from the LAI by a slightly modified (no dead leaf for crops, constant base SAI of 10 percent of maximum LAI) formulation of Lawrence and Chase (2007) and Zeng 
Hydrol. Earth Syst. Sci. Discuss., doi:10.5194/hess-2016-557, 2016

Manuscript under review for journal Hydrol. Earth Syst. Sci.

Published: 1 November 2016

et al. (2002) to better represent European tree types. Vegetation height was set to $7 \mathrm{~m}$ for needle-leaf trees, $10 \mathrm{~m}$ for broad-leaf trees to account for partial coverage by shrubs, and to $20-120 \mathrm{~cm}$ for crops and $10-60 \mathrm{~cm}$ for grass depending on the time of the year, with low values in the winter months and largest values in July and August. Since we consider only one crop type, we do not specify a harvest date when the plant height drops to its minimum, but assume a smooth decline between August 5 and October.

For the representation of soils in CLM we use the 1:1,000,000 soil map (BUEK1000) provided by the Federal Institute for Geosciences and Natural Resources $\quad$ BGR (http://www.bgr.bund.de/DE/Themen/Boden/Informationsgrundlagen/Bodenkundliche_Karten_Datenbanken/BUEK1000/bu ek1000_node.html)

10 This soil map is available for entire Germany; thus only small areas in Switzerland and France are missing outside the Neckar catchment for which we assume a nearby soil class. BUEK1000 offers sand and clay percentages as well as carbon content for two to seven soil horizons down to a maximum depth of $3 \mathrm{~m}$ for each soil type, which we transferred to the respective model layers by choosing the horizon found at the center of each model layer. For lower soil layers without BUEK1000 information the lowest horizon is assumed to extend down to the $3 \mathrm{~m}$ required for CLM. Carbon content is used to infer soil color. For urban areas (modeled as bare soil, as mentioned above) a fixed soil color (class 8 in CLM) was used different from land use classes with plants.

Simulations for Domain 1 were performed for a period of seven years (2007-2013). A 100-day spin-up (each day forced with atmospheric data from 01/01/2007) for CLM was performed prior to the simulation start, which created the virtual reality.

\subsection{Domain 2: Upper Neckar Catchment}

20 The upper Neckar catchment simulations with CLM-ParFlow were performed with 100m horizontal resolution for both submodels. The upper 10 layers of ParFlow and CLM are identical, while 40 layers were added in ParFlow down to $100 \mathrm{~m}$ depth to account for groundwater dynamics. Different from the rectangular Domain 1, Domain 2 contains only grid points within the Upper Neckar catchment, which reduces the computational and storage demand (compared to an encompassing rectangle domain) by about $50 \%$. The lowest atmospheric layer state variables simulated for Domain 1 are spline-interpolated to $100 \mathrm{~m}$

25 and used as atmospheric forcing.

Since soil properties may vary substantially at scales smaller than the $1 \mathrm{~km}$ for which BUEK1000 is appropriate, which might impact system dynamics (Binley et al. 1989, Herbst et al. 2006, Rawls 1983), the soil map of Domain 1 is downscaled by artificially adding variability using the following method:

(1) The BUEK1000 soil map is randomly sampled at 1995 point locations with one sample every 5 km2 on average, a

30 minimum sample distance of $250 \mathrm{~m}$, and at least one sample for each soil type of the original soil map. This strategy resulted from extensive testing by minimizing the tradeoffs between reproducing the main features of the original soil map and creating variability at finer resolution. 
Hydrol. Earth Syst. Sci. Discuss., doi:10.5194/hess-2016-557, 2016

Manuscript under review for journal Hydrol. Earth Syst. Sci.

Published: 1 November 2016

(c) Author(s) 2016. CC-BY 3.0 License.

(1) The sample locations are used as conditional points for further interpolation. Here, texture, carbon content and depth of the first three soil horizons are extracted from the BUEK1000.

(2) Experimental variograms and cross-variograms are calculated for all variables and exponential models were fitted to all spatial structures.

5 (3) Horizon depths and carbon content are interpolated based on ordinary kriging. Texture map (sand and clay percentage) is generated using a single realization based on conditional co-simulation (Gomez-Hernandez and Journal, 1993) to provide the sub-scale variability $(<1 \mathrm{~km} 2)$.

(4) Since ParFlow describes retention and hydraulic conductivity curves based on van-Genuchten-Mualem parameters, pedotransfer functions are applied to estimate these parameters. The pedotransfer functions of Cosby et al. (1984), Rawls

10 (1983) and Tóth et al. (2015) are used and selected based on data availability, applicability of the particular approaches, and previous evaluations conducted in the area (Tietje and Hennings, 1996).

Apart from the described changes in the soil map, the CLM setup is identical to the one for Domain 1. In order to keep soil porosity identical between CLM and ParFlow, we replaced the porosity calculation within CLM (which uses a different pedotransfer function). The Manning's surface roughness was set to a constant of $5.52 \times 10-4 \mathrm{~h} / \mathrm{m} 1 / 3$ and the specific storage

15 to $1 \times 10-3$. The chosen surface roughness value results in a realistic base flow for the local rivers without calibration. Repercussions of this choice are discussed in Chapter 6. Slopes in rivers are modified/smoothed to avoid artificial ponded areas.

In order to allow for realistic flow in the saturated zone, a 3-D geologic of the geological survey of the state of BadenWuerttemberg was used from which eleven rock types for Baden-Wuerttemberg were identified (see Figure 4). Nine of these

20 types can be found in the upper Neckar catchment albeit some only cover very small volumes. Tab. 1 summarizes porosity and hydraulic conductivity used in the virtual reality for the different stratigraphic units. It should be noted that karst features of limestones are not considered at all, and porosities in stratigraphic units containing limestones and crystalline rocks are generally chosen considerably higher than in nature.

Not covered in any of the data sets discussed and implemented so far are the large alluvial bodies filling large part of the

25 Neckar valley throughout the domain (Riva et al. 2006). As these bodies are highly conductive, they are also believed to be important for the regional groundwater flow and should be included in the model. Since the valleys in the model are often small compared to the limited horizontal resolution of the model, we conceptualize the alluvial bodies as gravel layers existing underneath all river cells (cells with a pressure head >0.1) and directly next to rivers (riverbanks) (i.e., one gridpoint besides each river cell). The gravel layers reach from beneath the soil down to a depth of $8 \mathrm{~m}$. The gravel cells are parameterized with

30 a high hydraulic conductivity of $1 \mathrm{~m} / \mathrm{h}$, a porosity of 0.6 and van-Genuchten parameters of 2 for $\mathrm{n}$ and 4 for $\alpha[1 / \mathrm{m}]$ (residual saturation is $0.06 \mathrm{~cm} 3 / \mathrm{cm} 3$ ). In reality, up to $30 \%$ of the runoff takes place in the subsurface, especially during periods of base flow. This is based on a calculation of the upper Neckar sub-catchment where we used measured gridded precipitation data as well as measured river discharge data at the outlet, combined with the virtual-reality data for evapotranspiration to calculate the water balance over a whole year to eliminate any influence of transient storage changes. This is possible as we used the 
Hydrol. Earth Syst. Sci. Discuss., doi:10.5194/hess-2016-557, 2016

Manuscript under review for journal Hydrol. Earth Syst. Sci.

Published: 1 November 2016

(c) Author(s) 2016. CC-BY 3.0 License.

year 2007 which was also used to perform the spin-up resulting in negligible storage difference between the years. About 30\% of the precipitation was neither evaporated nor discharged by the river. While our simulated evapotranspiration rates may be inaccurate, it is implausible to assume this can account for $30 \%$ of the precipitation. The only other method how the water could have left the domain is through the subsurface. Thus, gravel channels are needed to account for this lateral flow, as

5 otherwise subsurface outflow from the domain would be negligible. The gravel layers below the rivers allow for a reasonable distribution of surface and subsurface discharge at the outlet of the catchment and reasonable river - aquifer exchange fluxes. It should be noted that the model assumes no-flow boundary conditions at the subsurface domain boundaries. A very conductive $(100 \mathrm{~m} / \mathrm{h})$ layer close to the model outlet was included to enable the subsurface water to discharge back into the river and leave the model domain as the no-flux boundary condition forces the water to rise to the surface in order to leave the

10 domain. To avoid influence of this slightly artificial boundary, all observations considered are taken at a large enough distance from the outlet boundary.

\section{Demonstration Results}

In the following, we present some example results of the virtual-reality simulations in order to demonstrate its potential for a better understanding of the dynamics in coupled terrestrial systems and to show that it resembles reality well enough to serve 15 in the test of data-assimilation strategies. Figure 5 shows a snapshot of Domain 1 showing the three-dimensional distribution of cloud water/ice (greyscale), precipitation density (blue, foreground over grey clouds) as well as the volumetric soil moisture (colored). The soil shows different layers of soil moisture where changes are mainly connected to different soil hydraulic properties. Only clouds reaching high enough to have sufficient cloud ice produce precipitation and some precipitation evaporates before it reaches the ground. Extended weather fronts moving through the domain (not shown), which are imposed

20 by the boundary conditions, are also simulated quite realistically.

An important measure for hydro-meteorological interactions within a catchment is the relation between water availability and surface energy flux partitioning. The virtual reality should capture the expected reduced evapotranspiration (ET) with increasing distance to groundwater (e.g., Shrestha et al. 2014). For Domain 2 the mean ET values for March and April for the year 2007 (Figure 6) are calculated as the sum of canopy evaporation, ground evaporation and plant transpiration, while the distance to groundwater is calculated from pressure. All calculations are performed on 12 hourly output and averaged for the respective months. March was a rather wet month and lacked significant plant activity; thus ET is dominated by ground and canopy evaporation. April was almost completely dry (on average less than $3 \mathrm{~mm}$ precipitation over the domain) and transpiration increased related to leaf onset resulting in a larger contribution to total ET.

Figure 7 shows ET as a function of the distance to groundwater for the two months while Figure 8 presents a more in-depth 30 analysis for April with only bare soil grid cells considered. For bare-soil, ET is reduced if the distance to groundwater falls below $10-80 \mathrm{~cm}$, depending on soil properties. The drop in ET with falling distance to groundwater occurs at shallower distances to groundwater for increasing soil sand contents. Such relations are less obvious for cells with significant plant cover. 
Hydrol. Earth Syst. Sci. Discuss., doi:10.5194/hess-2016-557, 2016

Manuscript under review for journal Hydrol. Earth Syst. Sci.

Published: 1 November 2016

(c) Author(s) 2016. CC-BY 3.0 License.

While trees show overall higher ET and almost no ET change with distance to groundwater due to their deep root zones, ET variability increases with deeper distance to groundwater. Also crops and grassland show limited ET changes as function of distance to groundwater, which can be explained by the water availability (no water stress) in the time period considered.

\section{Plausibility Tests}

5 This section summarizes comparisons of the virtual reality with its real counterpart in terms of the statistics of model variables and derived virtual observations from satellite-based passive microwave sensors.

\subsection{Evaluation of Meteorological Variables in Domain 1 (Entire Neckar Catchment)}

Precipitation is the strongest hydrological driver in this region, highlighting the importance of its realistic spatial and temporal variability in the virtual reality including its statistical relations with topography. Also, the state of the atmospheric boundary layer, which reflects the interaction of the land surface with the atmosphere is a critical component of the terrestrial system, which should be represented by the virtual reality with some confidence.

\subsubsection{Precipitation}

The regionalized daily precipitation data set (REGNIE) of the German Weather Service (DWD) is used for the evaluation of the simulated spatial precipitation patterns for the years 2007 - 2013. REGNIE is based on precipitation observations at DWD

15 observational stations, which are interpolated onto a $1 \mathrm{~km} 2$ grid (Rauthe et al. 2013). In addition, hourly observations of some stations (Figure A 1) are used to evaluate seasonal daily cycles.

The simulated annual mean precipitation (Figure 9) is governed by the orographic structures of the Black Forest and Swabian Alb. Simulated values range between approximately $520 \mathrm{~mm} /$ year in the vicinity of Mannheim (NW of Domain 1) and 2170 $\mathrm{mm} /$ year over the Black Forest in accordance with REGNIE concerning the overall pattern and range (REGNIE: $510 \mathrm{~mm} /$ year

$20-2130 \mathrm{~mm} / \mathrm{year}$ ). Overall the virtual reality overestimates precipitation in the east and south and underestimates it in the north and west by about $20 \%$. The seasonal differences are similar in pattern but stronger. During winter (December to February), when precipitation is dominated by advection, the westerly winds result in maxima over the upwind zones of the mountains and their peaks and leeward minima. Also the simulated seasonal patterns compare well with REGNIE, but the virtual reality overestimates precipitation over the mountains and the south-eastern part of the Neckar catchment. Such differences have also been found for COSMO coupled to its own TERRA land surface model with the same spatial resolution (e.g., Dierer et al., 2009; Lindau and Simmer, 2013). During summer (June to August) cloud bases are usually higher and reduce luff-lee effects. Moist air extends further to the east and south and gets staunched by the alpine upland leading to enhanced precipitation there. In addition, convective precipitation dominates during the summer season. The summer precipitation pattern of the virtual reality resembles the REGNIE pattern, but amounts are about $20 \%$ lower over large parts of the catchment (Figure 9). 
Hydrol. Earth Syst. Sci. Discuss., doi:10.5194/hess-2016-557, 2016

Manuscript under review for journal Hydrol. Earth Syst. Sci.

Published: 1 November 2016

(c) Author(s) 2016. CC-BY 3.0 License.

The mean seasonal diurnal precipitation cycles (Figure 10) reflect the dominating precipitation types. While observed and simulated winter precipitation (Figure 10b) do not show a diurnal cycle, summer precipitation (Figure 10a) increases over the afternoon reaching a maximum at about $7 \mathrm{pm}$ in accordance with the maximum of convective precipitation. The simulations reproduce this pattern but exhibit a weak second peak between $6 \mathrm{am}$ and 12am while the afternoon/evening increase is delayed

5 by about two hours. Also the simulated daily precipitation distribution fits the observations quite well. While the virtual reality has somewhat less dry and low precipitation days than REGNIE, the number of days between 4 and $10 \mathrm{~mm}$ are higher than in REGNIE (not shown). The simulated and observed seasonal precipitation cycles (Figure 11) compare very well and mean precipitation is nearly identical between simulations and observations. The VR reproduces also quite well - although less pronounced in summer - the seasonal cycle of maximum daily precipitation (see also Dierer et al. 2009).

\section{$10 \quad$ 5.1.2 Atmospheric State Variables and Surface Radiation}

We compare the atmospheric boundary layer $(\mathrm{ABL})$ of the virtual reality to observations from the meteorological tower at the Karlsruhe Institute of Technology (KIT; Kalthoff and Vogel, 1992) and with DWD radiosonde observations at Stuttgart (STG) (see Figure 3 for locations and Tab A1 for details of observed quantities). To avoid a biased comparison due to land-cover mismatches between the virtual reality and the actual land use at the observation sites, the simulations are averaged over five-

15 by-five grid boxes around the observation sites.

The $10 \mathrm{~m}$ mean diurnal minimum temperatures in the virtual reality are between $0.5 \mathrm{~K}$ (January) and $2.5 \mathrm{~K}$ (August) higher than observed (Figure 12, top), and they are reached approximately one hour later than observed while the subsequent morning temperature rise is shifted about one hour compared to the KIT observations. The simulated diurnal temperature maxima are on average $0.7 \mathrm{~K}$ lower than in the observations and are reached up 30 minutes later than measured. The morning temperature

20 gradient in the virtual reality ranges from $0.10 \mathrm{Kh}-1$ in December to $0.31 \mathrm{Kh}-1$ in April and compare reasonably well to the observations (0.13/0.52 Kh-1 in January/April). The evening cooling, however, progresses too slowly in the virtual reality and results in too high diurnal minimum temperatures. At $100 \mathrm{~m}$ above ground, diurnal maximum temperatures agree to within 0.7 $\mathrm{K}$ while the warm bias of diurnal minimum temperatures in the virtual reality is reduced to $0.9 \mathrm{~K}$ compared to the surface values (Figure 12, bottom). The $1 \mathrm{~h}$ time shift between the diurnal minimum temperatures and the morning temperature rise at $100 \mathrm{~m}$ are similar to the $10 \mathrm{~m}$ results. In $200 \mathrm{~m}$ height, the monthly mean diurnal cycles of the virtual reality and the KIT observations are practically identical (not shown). The temperature standard deviations of the virtual reality are somewhat smaller than observed, in particular during the afternoon for the summer half year when the reduction can be more than $20 \%$. COSMO in TerrSysMP estimates atmospheric-boundary-layer heights via the bulk Richardson number criterion with a threshold of 0.22 for unstable and 0.33 for stable conditions (Szintai and Kaufmann, 2008). Both seasonal and diurnal

30 variations of mean atmospheric-boundary-layer height at 0 and $12 \mathrm{~h}$ local time agree well with the observations using the same criterion (Figure 12), but the virtual reality tends to overestimate atmospheric-boundary-layer heights at nighttime by up to $150 \mathrm{~m}$ and underestimate it at daytime (up to $200 \mathrm{~m}$ in March). In Figure 14, we compare mean vertical profiles of temperature, virtual potential temperature, and specific humidity of the virtual reality to radiosonde observations at $0 \mathrm{~h}$ and $12 \mathrm{~h}$ local time 
Hydrol. Earth Syst. Sci. Discuss., doi:10.5194/hess-2016-557, 2016

Manuscript under review for journal Hydrol. Earth Syst. Sci.

Published: 1 November 2016

(c) Author(s) 2016. CC-BY 3.0 License.

at Stuttgart (STG) including the mean differences (bias) and the standard deviation of the differences. The virtual reality is up to $0.9 \mathrm{~K}$ warmer close to the surface at $0 \mathrm{~h}$ and up to $0.5 \mathrm{~K}$ colder at $12 \mathrm{~h}$. At larger heights, the virtual reality is up to $0.5 \mathrm{~K}$ warmer depending on land cover. Specific humidity profiles at $0 \mathrm{~h}$ differ only little; the virtual reality is approximately $0.2 \mathrm{gkg}$ 1 too dry close to the surface and $0.2 \mathrm{gkg}-1$ too wet above $1500 \mathrm{~m}$. At $12 \mathrm{~h}$ the virtual reality is up to $0.3 \mathrm{gkg} 1$ too wet

5 throughout the entire profile. The virtual reality has smaller virtual potential temperature gradients and is thus less stable close to the surface at $0 \mathrm{~h}$. At $12 \mathrm{~h}$, the virtual reality does not capture the decreasing virtual potential temperature close to the surface and tends towards a more neutral instead of unstable profile at low heights.

At KIT (STG) the land surface in the virtual reality receives on average $20 \mathrm{Wm}-2(7 \mathrm{Wm}-2)$ more incoming shortwave radiation and $18 \mathrm{Wm}-2(10 \mathrm{Wm}-2)$ less incoming longwave radiation indicating a somewhat lower cloud cover (or lower optical depth)

10 as observed. At daytime $(6 \mathrm{~h}-22 \mathrm{~h})$, the mean outgoing longwave radiation of the virtual reality matches the KIT observations, while at nighttime ( $22 \mathrm{~h}-6 \mathrm{~h}$ ) values are $7.2 \mathrm{Wm}-2$ larger than observed, which corresponds to a higher surface temperature of approximately $1.4 \mathrm{~K}$.

Overall, the atmospheric profiles of the virtual reality, including the atmospheric-boundary-layer heights, compare very well with observations. Noteworthy differences only occur close to the surface with too high nighttime temperatures (up to $2.5 \mathrm{~K}$

15 in summer) and subsequently too small morning temperature gradients. Somewhat higher incoming shortwave and lower incoming longwave radiation at the surface indicate less cloud cover (or lower cloud optical depths) in the virtual reality compared to the observations. These results are in line with a previous evaluation of a $2.2 \mathrm{~km} \mathrm{COSMO}$ simulation (Ban et al. 2014). In addition, we note somewhat reduced unstable conditions at daytime close to the surface in the simulations.

\subsubsection{Passive Microwave Observations}

20 The most direct area-covering observations of soil moisture are currently provided by L-Band (1.4 GHz) passive microwave observations from satellites. The Community Microwave Emission Model (CMEM) is used as a forward operator to simulate the brightness temperatures (TB) at this frequency in vertical and horizontal polarization (de Rosnay et al., 2009). CMEM simulates brightness temperatures at the top of the atmosphere (TOA) resulting from microwave emission and interaction by soil, vegetation, and atmosphere based on the state variables of the virtual reality. Input to CMEM are the percentages of soil clay and sand, percentage of water in the domain, the profiles of soil moisture and soil temperature, vegetation types and LAI. Satellite orbit geometry, antenna pattern, foot-print and incidence angle are taken into account following the NASA SMAP (Soil Moisture Active Passive) radiometer specifications, i.e. a full-width-half-maximum field of view of $2.4^{\circ}$ leading to a footprint of $36 \mathrm{~km}$ across-orbit and $47 \mathrm{~km}$ along-orbit, and a $41^{\circ}$ incidence angle (Chan et al., 2015). This antenna pattern is applied for weighing the simulated brightness temperatures on the grid of Domain 1 (Figure 15, left) in order to obtain virtual

30 SMAP observations. Finally, the synthetic observations are rendered according to the Equal-Area Scalable Earth grid (EASEgrid) with a $36 \times 36 \mathrm{~km}$ grid of the SMAP L1C TB database (Figure 15, right), which can then be compared with real observations for the indirect evaluation of the virtual reality. Every EASE-grid corresponds to a fixed geo-location for real SMAP satellite overpass over the virtual reality. 
Hydrol. Earth Syst. Sci. Discuss., doi:10.5194/hess-2016-557, 2016

Manuscript under review for journal Hydrol. Earth Syst. Sci.

Published: 1 November 2016

(c) Author(s) 2016. CC-BY 3.0 License.

We evaluate the simulated mean states of Domain 1 for the years 2009 to 2013 by comparison with real SMAP observations from April 2015 to March 2016; thus only statistical comparisons can be made. We did not yet compare with SMOS observations, which are available for the time period of the virtual-reality simulations, because of severe quality limitations by radio-frequency interference (RFI) effects over the region. Our initial results with commonly used parameters for surface roughness and vegetation in CMEM lead to a systematic underestimation of brightness temperature by the virtual reality of about $-60 \mathrm{~K}$ (see orange line in Figure 16, which compares true SMAP observations with the simulated brightness temperatures), which can only partially be attributed to too large near-surface soil moisture values of the virtual reality. The cumulative distribution functions of the satellite-derived soil moisture products and the soil moisture of the virtual reality suggest an about $45 \%$ higher near-surface soil moisture of the virtual reality compared to the satellite estimates (Saavedra et

10 al. 2016, Figure 6). Figure 16 compares true SMAP observations with simulated brightness temperatures obtained with and without correcting for the soil-moisture bias of the virtual reality. The correction decreases the bias of the virtual reality in brightness temperature from $-60 \mathrm{~K}$ to about $-22 \mathrm{~K}(-6 \mathrm{~K})$ for the horizontal (vertical) polarization (Saavedra et al. 2016). This remaining bias can be further reduced by tuning the radiation interaction parameters in CMEM and by a better treatment of vegetation in CMEM; the latter may cause a bias of up to $20 \mathrm{~K}$ given the abundant and dense vegetation cover in the area. This hypothesis is corroborated by the lower bias of the virtual reality during winter-time, when the LAI is low. These biases will be addressed in the near future by better exploiting the uncertainty of the radiation interaction parameters and by including in CMEM a two-stream approximation to better simulate cases with dense vegetation.

The microwave observations constructed from the virtual reality show a typical situation for data assimilation; more often than not there are biases between simulated and remote sensing observations. This discrepancy usually has multiple causes, which

20 can relate to the observations themselves, assumptions in the forward operator used to simulate the virtual observations, and in the model used to generate the systems state variables entering the forward operator. Even if these differences cannot be removed, such observations are highly valuable for data assimilation as long as temporal tendencies are meaningful. Usually the bias is statistically corrected and thus only the information in the temporal and (if meaningful) spatial variability of the observations is exploited for moving the model states towards the true states.

\section{$25 \quad 5.1 .4 \quad$ Conclusions}

The comparison of Domain 1 of the virtual reality with observations has shown a quite satisfactory match for precipitation and thermodynamic states of the atmospheric boundary layer. Both the seasonal cycles of precipitation and even daily extreme values are reproduced with good accuracy. Notable is a slightly lower cloud cover in the virtual reality compared to observations, which affects in particular the near-surface temperature gradients. The differences with passive microwave observations have revealed large biases, which have to be corrected prior to any data assimilation effort. 
Hydrol. Earth Syst. Sci. Discuss., doi:10.5194/hess-2016-557, 2016

Manuscript under review for journal Hydrol. Earth Syst. Sci.

Published: 1 November 2016

(c) Author(s) 2016. CC-BY 3.0 License.

\subsection{Evaluation of River Discharge in Domain 2 (Upper Neckar Catchment)}

We compare river discharge in Domain 2 of the virtual reality with observations made in the upper Neckar catchment at the gaging station Kirchentellinsfurt (Figure 17), which is sufficiently far away from the domain boundary to exclude impacts of the no-flow lateral boundary conditions in the subsurface on river discharge (see discussion at the end of Section 3.2). The range of the hydrological response to precipitation in the virtual reality is in good agreement with the observations; this is noteworthy since no calibration to runoff data has been applied to the model. In the following, however, we discuss three features showing differences between virtual-reality simulations and observations. In winter, the simulated discharge peaks are delayed compared to the observations by about three days. A reason could be a too large Manning's coefficient in the virtual reality, which would lead to a less flashy flow regime. In the discussion we make a suggestion how the Manning coefficient could be parameterized to account for the mismatch between true river width and the model resolution (100 $\mathrm{m}$ in Domain 2) in order to better represent realistic flood dynamics. During spring and summer, the response in the virtual reality to precipitation is significantly smoother than observed. The differences between observed and simulated precipitation discussed above and the effects of the less predictable convective events during these seasons may also play a significant role. Convective events will always be displaced in space and time in the virtual reality compared to the observations and may even

15 show different individual life cycles including lifetime and amplitude. Finally, the base flow in the virtual reality is higher than in the real catchment in summer time, possibly due to higher groundwater levels or smaller actual evapotranspiration in the virtual reality compared to the real catchment.

Figure 18a, compares the flow duration curves, which represent the statistical probability to exceed a specific discharge value within a given time period. The year 2007, for which the comparisons are made, is quite representative for the past 40 years.

20 The virtual reality shows similar probability for high discharge rates but has smaller probabilities for (very) low discharge rates compared to the observations (note, however, the log scale used in the figure). The smaller probabilities for (very) low discharge rates could also be attributed to higher groundwater levels in the virtual reality, which enhance the river base flow. The virtual reality produces lower runoff coefficients (ratio between runoff and precipitation over the catchment area) than observed for the year 2007 from December to May but higher coefficients during the rest of the year (Figure 18b). We hypothesize that the virtual reality has a lower winter and springtime hydrological response due to missing subsurface heterogeneity. As stated above, we have neglect karst features, which are known to produce fast lateral subsurface flows. The higher response in summer and fall is probably a result of the stronger groundwater contributions as previously discussed.

Overall, the model represents general statistical features of the catchment, including the typical seasonal trends, quite well while differences are noted related to hydrological extremes. These differences could be reduced by extensive model calibration from which we refrain because hydrological extremes are not primary the objective of the virtual reality. 
Hydrol. Earth Syst. Sci. Discuss., doi:10.5194/hess-2016-557, 2016

Manuscript under review for journal Hydrol. Earth Syst. Sci.

Published: 1 November 2016

(c) Author(s) 2016. CC-BY 3.0 License.

\section{Discussion}

We experienced several challenges in the setup of the virtual reality. In the following, we will discuss four of them, which we believe to be not specific to our model, but are inherent to the challenge of simulating flow processes at the catchment scale including the energy and mass fluxes across compartment boundaries with physically-based, high-resolution coupled models.

5 The size of the catchments considered still poses an enormous challenge in terms of required CPU-time (see next paragraph), thus the applicability of Darcy's law with laboratory-scale parameters for the spatial resolution ( 100 m for Domain 2) used is still questionable. On this scale, we still have to resort to apparent model parameters to produce realistic mass fluxes in the compartments.

IT requirements: The total number of grid cells for Domain 2 is 562,682 per model layer. With 10 layers of CLM and 50

10 layers of ParFlow, this results in 33.7 million grid cells of which about 16 million are active for computation. This simulation requires on average 8 hours to advance 5 days using 1024 cores of the BlueGeneQ machine JUQUEEN at the Juelich Supercomputing Centre (http://www.fz-juelich.de/ias/jsc/EN/Home/home_node.html). The same resolution applied for Domain 1 will have 10 times more active grid points. Thus 8192 cores are needed for this simulation as well as approximately 6 million core-h per simulation year computing time with the goal to run for at least five years to create a long enough time

15 series. The efficient use of so many grid cells is not possible with CLM3.5; thus we have to update TerrSysMP to include CLM4.5, in order to removes this bottleneck.

Representation of rivers and surface roughness: River flow in the ParFlow module of TerrSysMP is taken care of by an overland flow module. Overland flow appears in ParFlow as soon as hydraulic heads in the top cells are above the land surface. As there is no discrimination between overland flow and river flow, rivers in the virtual reality have the width of the grid

20 resolution (100 $\mathrm{m}$ for Domain 2) whereas the real rivers may be significantly narrower. Overland flow is represented in ParFlow with the kinematic wave approximation of the St Venant equations with the surface friction represented by Manning's coefficient. A realistic river Manning's coefficient assigned to a $100 \mathrm{~m}$ grid cell (while in fact the river is narrower) would result in too high discharge values during rain events and far too low ones during dry periods. In both cases the too low water levels (caused by the too wide rivers) results in a poor representation of river-subsurface exchange. Our current choice for the

25 VR $(5.52 \times 10-4 \mathrm{~h} / \mathrm{m} 1 / 3)$ results in realistic average discharge throughout the year, but in too low flow velocities. In order to compensate for the coarse model resolution leading to an incorrect representation of the river width, the Manning's coefficient could be scaled such that the overland flow velocity in river cells equals the river flow velocity. A realistic flow velocity v would improve the phasing between simulated and observed discharge. The discharge peak signal will also change with the changed flow velocity caused by modified Manning's coefficient values. In principle it is possible to scale the Manning's 30 coefficient in river grid cells such that the velocities agree if the true river widths (and true Mannung's coefficients) are known. Also the hydraulic conductivity of the model top layer for river cells could be scaled in order to reduce the loss of too much surface water to the subsurface caused by the larger-than-real river cells. All these issues will become much more severe if 
Hydrol. Earth Syst. Sci. Discuss., doi:10.5194/hess-2016-557, 2016

model resolutions are lowered, e.g. for the model versions applicable for ensemble-base data assimilation, which will make the adjustments proposed here even more important.

Coarsening of topography: The coarse topography of the virtual reality reduces the true hill slopes where lateral flow on the surface and in the shallow subsurface takes place. This affects quick flow components towards rivers. As shown in Shresta et

5 al. (2015) coarse topography directly impacts the storage of water in the unsaturated zone and soil moisture as drainage becomes less effective. This in turn can lead to an overestimation of latent and underestimation of sensible heat flux. Additionally, coarse-resolution model runs result in delayed and stretched discharge peaks in the rivers. The severity of this effect is proportional to the degree of topography smoothing that is introduced by the coarser resolution and therefore any change in subsurface parameters like e.g. conductivity will depend on the degree of coarsening and the location within a catchment. Especially in narrow valleys and in mountainous areas this will lead to an overestimation of soil moisture, which we have not yet compensated by changing other parameters.

Soil parameters: As outlined in section 2, the soil hydraulic parameters were generated based on soil maps of the real Neckar catchment. According to the maps, the soils in the catchment consist mainly of clay and silt, which have rather low saturated hydraulic conductivities and small air entry pressure values. In our first simulations, the water content was in large areas close

15 to saturation, even for upper soil layers, and the infiltration velocities were unrealistically slow. One reason is that the soil parameters do not capture the true soil heterogeneity and that infiltration happens in reality often in root channels, small fractures, and other small structures. Thus, infiltration is always under predicted by models using observed soil parameters assuming homogeneity. Such infiltration processes may be captured with dual domain approaches, which are, however, computationally demanding. A specific workaround would be to change the soil hydraulic parameters in order to obtain

20 stronger infiltration. Currently, we test an artificially increased sand percentage of the soils in order to stay consistent with the concept of the pedotransfer functions used in CLM. We will also test known scaling rules (e.g., Ghanbarian et al., 2015) to increase for example the saturated hydraulic conductivity for larger soil units. These rules should be applied on the soil hydraulic parameters, estimated by the pedotransfer functions.

\section{Conclusions and Outlook}

25 Using a virtual reality (VR) for the integrated subsurface-land surface-atmosphere system as a testbed for cross-compartmental data assimilation is a viable concept if the fidelity of the virtual reality is high enough to consider all important processes in a reasonable way. Plausibility tests for the derived virtual reality based on TerrSysMP, which tries to mimic the Neckar catchment in southwestern Germany, show that the virtual reality is able to reproduce realistic behavior when compared to measurements, especially for the atmosphere. Comparisons of simulated precipitation and atmospheric boundary layer

30 statistics in the virtual reality show a very reasonable agreement with real observations. However, comparing the results of the virtual reality to passive microwave remote sensing measurements by satellites shows clearly a systematic bias which is probably related to a mixture of systematic errors in the remote sensing measurements, assumptions in the used forward 
Hydrol. Earth Syst. Sci. Discuss., doi:10.5194/hess-2016-557, 2016

Manuscript under review for journal Hydrol. Earth Syst. Sci.

Published: 1 November 2016

(c) Author(s) 2016. CC-BY 3.0 License.

operator, parameterizations of land surface properties (soil parameters) in the virtual reality, and missing processes therein (e.g., preferential flow, hill-slope processes). Overall the results are encouraging regarding the viability of the virtual reality concept as key input parameters to the land surface and subsurface show very good agreement with measurements.

The analysis of the virtual reality for the higher resolved upper Neckar catchment shows a realistic connection between

5 evapotranspiration and distance to groundwater. By contrast, larger deviations to reality are found for river discharge dynamics. The deficiencies could be traced to the model resolution, which limits the often much smaller river widths to multiples of the model resolution, and to the way river discharge is handled in the ParFlow component of TerrSysMP. A new parameterization scheme is proposed to avoid such problems in future model simulations. The main issue we face for the upper Neckar are too high soil moisture and shallow groundwater levels. Several ideas have been proposed to improve the setup.

10 Overall the results are satisfying, and there are no major issues with respect to using the virtual reality as a basis for dataassimilation experiments. Having confirmed this, we are now able to extract virtual observations from any compartment of a fully coupled version of the Neckar catchment. This will provide us with the ability to develop and test various data assimilation methods for assimilating observations across compartments. Despite of this, more sophisticated versions of the virtual reality (higher resolution, improved parameterization of sub-scale processes as discussed above) are even more valuable and already

15 in progress. In a real-world data assimilation framework, the model used for data assimilation will always show systematic differences to reality, and we will face very similar issues as we did when comparing our virtual reality with true observations. The most prominent will be caused by the even coarser topography which affects surface runoff, soil moisture content, and land-atmosphere exchanges fluxes, and thus also the atmospheric boundary layer.

\section{Acknowledgements}

20 This research is funded by the Deutsche Forschungsgemeinschaft (DFG, FOR2131: "Data Assimilation for Improved Characterization of Fluxes across Compartmental Interfaces"). Computing time has been provided by the Gauss Centre for Supercomputing (http://www.gauss-centre.eu/gauss-centre/EN/Home/home_node.html) and the Facilities are operated by the Juelich Supercomputing Centre (http://www.fz-juelich.de/ias/jsc/EN/Home/home_node.html). We thank the members of HPSC-TerrSys (http://www.hpsc-terrsys.de/hpsc-terrsys/EN/Home/home_node.html) and Klaus Goergen in particular for invaluable technical support with the JUQUEEN supercomputer. Furthermore, we thank Prabhakar Shresta and Mauro Sulis for their preliminary work and introduction to the TerrSysMP modeling platform.

\section{References}

Alkama, R., Papa, F., Faroux, S., Douville, H., and Prigent, C.: Global off-line evaluation of the ISBA-TRIP flood model, Climate Dyn., 38, 1389-1412, doi:10.1007/s00382-011-1054-9, 2012. 
Hydrol. Earth Syst. Sci. Discuss., doi:10.5194/hess-2016-557, 2016

Manuscript under review for journal Hydrol. Earth Syst. Sci.

Published: 1 November 2016

(c) Author(s) 2016. CC-BY 3.0 License.

Ashby, S.F., and Falgout R. D.: A parallel multigrid preconditioned conjugate gradient algorithm for groundwater flow simulations, Nuclear Science and Engineering, 124(1), 145-159,1996.

Avissar, R., and Pielke, R. A.: A parameterization of heterogeneous land surfaces for atmospheric numerical models and its impact on regional meteorology. Monthly Weather Review, 117(10), 2113-2136, doi:10.1175/1520-

5 0493(1989)117<2113:APOHLS>2.0.CO;2,1989.

Baldauf, M., Seifert, A., Foerstner, J., Majewski, D., Raschendorfer, M., and Reinhardt, T.: Operational convective-scale numerical weather prediction with the COSMO model: description and sensitivities. Monthly Weather Review, 139(12), 38873905, doi:10.1175/MWR-D-10-05013.1,2011.

Ban, N., Schmidli, J., and Schaer, C.: Evaluation of the convection-resolving regional climate modelling approach in decade-

10 long simulations. J. Geophys. Res. Atmos., 119, 7889-7907, doi:10.1002/2014JD021478,2014.

Bashford, K. E., Beven, K. J., and Young, P. C.: Observational data and scale-dependent parameterizations: explorations using a virtual hydrological reality. Hydrological Processes 16, 293-312. doi:10.1002/hyp.33,2002.

Binley, A., Elgy, J., and Beven, K.: A physically based model of heterogeneous hillslopes: 1. Runoff production. Water Resources Research, 25, 1219-1226. doi:10.1029/WR025i006p01219,1989.

15 Chan, S., Njoku, E., and Colliander, A.: SMAP L1C Radiometer Half-Orbit 36 km EASE-Grid Brightness Temperatures. Version 2. Boulder, Colorado USA: NASA National Snow and Ice Data Center Distributed Active Archive Center. doi:10.5067/Y9C3Q3060AZ5,2015.

Chaney, N. W., Roundy, J. K., Herrera-Estrada, J. E., and Wood, E. F. (2015): High-resolution modeling of the spatial heterogeneity of soil moisture: Applications in network design. Water Resources Research 51, 619-638. 20 doi:10.1002/2013WR014964,2015.

Cosby, B. J., Hornberger, G. M., Clapp, R. B., and Ginn, T. R.: A Statistical Exploration of the Relationships of Soil Moisture Characteristics to the Physical Properties of Soils. Water Resour. Res., 0, 682-690. doi:10.1029/WR020i006p00682,1984. de Rosnay, P., Drusch, M., Boone, A., Balsamo, G., Decharme, B., Harris, P., Kerr, Y., Pellarin, T., Polcher, J., and. Wigneron, J. P.: AMMA Land Surface Model Intercomparison Experiment coupled to the Community Microwave Emission Model:

25 ALMIP-MEMP. Journal Geophysical Research, 114, D05108, doi:10.1029/2008JD010724,2009.

Dierer, S., Arpagaus, M., Seifert, A., Avgoustoglou, E., Dumitrache, R., Grazzini, F., Mercogliano, P., Milelli, M., and Starosta, K.: Deficiencies in quantitative precipitation forecasts: sensitivity studies using the COSMO model. Meteorologische Zeitschrift, 18 (6), 631-645, doi:10.1127/0941-2948/2009/0420,2009.

Gasper, F., Goergen, K., Shrestha, P., Sulis, M., Rihani, J., Geimer, M., and Kollet, S.: Implementation and scaling of the fully

30 coupled Terrestrial Systems Modeling Platform (TerrSysMP) in a massively parallel supercomputing environment-a case study on JUQUEEN (IBM Blue Gene/Q). Geoscientific model development discussions, 7, 3545-3573, doi:10.5194/gmdd-7-3545$2014,2014$.

Gomez-Hernandez, J., Journel J., and Journel, A. G.: Joint Sequential Simulationof MultiGaussian Fields, in Troia '92, Amilcar Soares (Ed.), volume 1, pages 85-94, Kluwer Academic Publishers, 1993. 
Hydrol. Earth Syst. Sci. Discuss., doi:10.5194/hess-2016-557, 2016

Manuscript under review for journal Hydrol. Earth Syst. Sci.

Published: 1 November 2016

(c) Author(s) 2016. CC-BY 3.0 License.

Fatichi, S., Vivoni, E. R., Ogden, F. L., Ivanov, V. Y., Mirus, B., Gochis, D., Downer, C. W., Camporese, M., Davison, J. H., Ebel, B., Jones, N., Kim, J., Mascaro, G., Niswonger, R., Restrepo, P., Rigon, R., Shen, C., Sulis, M., and Tarboton, D.: An overview of current applications, challenges, and future trends in distributed process-based models in hydrology. J. Hydrol. 537, 45-60. doi:10.1016/j.jhydrol.2016.03.026,2016.

5 Ghanbarian, B., Taslimitehrani, V., Dong,, G., and Pachepsky, Y. A.: Sample dimensions effect on prediction of soil water retention curve and saturated hydraulic conductivity. Journal of Hydrology. 528,127-137, doi:10.1016/j.jhydrol.2015.06.024,2015.

Haefliger, V., Martin, E., Boone, A., Habets, F., David, C. H., Garambois, P.-A., Roux, H., Ricci, S., Berthon, L., Thévenin, A., and Biancamaria, S.: Evaluation of Regional-Scale River Depth Simulations Using Various Routing Schemes within a

10 Hydrometeorological Modeling Framework for the Preparation of the SWOT Mission, Journal of Hydrometeorology, 16, 1821-1842, doi:10.1175/JHM-D-14-0107.1,2015.

Hendricks Franssen, H. J., Alcolea, A., Riva, M., Bakr, M., Van der Wiel, N., Stauffer, F., and Guadagnini, A.: A comparison of seven methods for the inverse modelling of groundwater flow. Application to the characterisation of well catchments, Adv. Water. Resour., 32 (6), 851-872, doi:10.1016/j.advwatres.2009.02.011,2009.

15 Herbst, M., Diekkrueger, B., and Vanderborght J.: Numerical experiments on the sensitivity of runoff generation to the spatial variation of soil hydraulic properties. Journal of Hydrology, 326, 43-58. doi:10.1016/j.jhydrol.2005.10.036,2006.

Jones, J. E., and Woodward C. S.: Newton-Krylov-multigrid solvers for large-scale, highly heterogeneous, variably saturated flow problems. Advances in Water Resources, 24(7), 763-774, 2001.

Kalnay, E.: Atmospheric modeling, data assimilation and predictability - Cambridge University Press, 341 pp,2003.

20 Kalthoff, N., and Vogel, B.: Counter-current and channelling effect under stable stratification in the area of Karlsruhe. Theor. Appl. Climatol., 45(2), 113-126, doi:10.1007/BF00866400,1992.

Kollet, S. J., and Maxwell, R. M.: Integrated surface-groundwater flow modeling: A free-surface overland flow boundary condition in a parallel groundwater flow model. Advances in Water Resources, 29(7), 945-958, doi:10.1016/j.advwatres.2005.08.006,2006.

25 Kollet, S. J., Maxwell, R. M., Woodward, C. S., Smith, S., Vanderborght, J., Vereecken, H., and Simmer, C.: Proof of concept of regional scale hydrologic simulations at hydrologic resolution utilizing massively parallel computer resources. Water Resources Research, 46(4), doi:10.1029/2009WR008730,2010.

Kurtz, W., He, G., Kollet, S. J., Maxwell, R. M., Vereecken, H., and H. Franssen, H.-J.: TerrSysMP-PDAF version 1.0): a modular high-performance data assimilation framework for an integrated land surface-subsurface model. Geoscientific Model

30 Development, 9(4), 1341-1360, doi:10.5194/gmd-9-1341-2016,2016.

Larsen, M. A. D., Refsgaard, J. C., Drews, M., Butts, M. B., Jensen, K. H., Christensen, J. H., and Christensen, O. B.: Results from a full coupling of the HIRHAM regional climate model and the MIKE SHE hydrological model for a Danish catchment, Hydrol. Earth Syst. Sci., 18, 4733-4749, doi:10.5194/hess-18-4733-2014, 2014. 
Hydrol. Earth Syst. Sci. Discuss., doi:10.5194/hess-2016-557, 2016

Manuscript under review for journal Hydrol. Earth Syst. Sci.

Published: 1 November 2016

(c) Author(s) 2016. CC-BY 3.0 License.

Lawrence, P. J., and Chase, T. N.: Representing a new MODIS consistent land surface in the Community Land Model (CLM 3.0). J. Geophys. Res., 112, G01023, doi:10.1029/2006JG000168,2007.

Lindau, R., and Simmer C.: On correcting precipitation as simulated by the regional climate model COSMO-CLM with daily rain gauge observations. Meteorology and Atmospheric Physics, 119, 1-2, p.31-42, doi:10.1007/s00703-012-0215-7,2013.

5 Mackay, E. B., Wilkinson, M. E., Macleod, C. J. A., Beven, K., Percy, B. J., Macklin, M. G., Quinn, P. F., Stutter, M., and Haygarth, P. M.: Digital catchment observatories: A platform for engagement and knowledge exchange between catchment scientists, policy makers, and local communities. Water Resour. Res., 51(6), 4815-4822. doi:10.1002/2014WR016824,2015. Myneni, R. B., Hoffman, S., Knyazikhin, Y., Privette, J. L., Glassy, J., Tian, Y., Wang, Y., Song, X., Zhang, Y., Smith, G. R., Lotsch, A., Friedl, M., Morisette, J. T., Votava, P., Nemani, R. R., and Running, S. W.: Global products of vegetation leaf area

10 and fraction absorbed PAR from year one of MODIS data. Remote Sensing of Environment, 83(1), 214-231, doi:10.1016/S0034-4257(02)00074-3,2002.

Oleson, K. W., Niu, G. Y., Yang, Z. L., Lawrence, D. M., Thornton, P. E., Lawrence, P. J., and Qian, T.: Improvements to the community land model and their impact on the hydrological cycle. Journal of Geophysical Research: Biogeosciences (20052012), 113(G1), doi:10.1029/2007JG000563,2008.

15 Poltoradnev, M., Ingwersen, J., and Streck, T.: Spatial and temporal variability of soil water content in two regions of Southwest Germany during a three-year observation period. Vadose Zone Journal, 15(6), doi:10.2136/vzj2015.11.0143,2016. Rauthe, M., Steiner, H., Riediger, U., Mazurkiewicz, A., and Gratzki, A. (2013): A Central European precipitation climatology - Part I: Generation and validation of a high-resolution gridded daily data set (HYRAS), Vol. 22(3), p 235-256, doi:10.1127/0941- 2948/2013/0436,2013.

20 Rawls, W. J.: Estimating soil bulk density from particle size analysis and organic matter content. Soil Sci., 135 (2), 123 125,1983 .

Ridler, M. E., van Velzen, N., Hummel, S., Sandholt, I., Falk, A. K., Heemink, A., and Madsen, H.: Data assimilation framework: linking an open data assimilation library (OpenDA) to a widely adopted model interface (OpenMI), Environ. Modell. Softw., 57, 76-89, doi:10.1016/j.envsoft.2014.02.008, 2014.

25 Riva, M., Guadagnini, L., Guadagnini, A., Ptak, T., and Martac, E. (2006): Probabilistic study of well capture zones distribution at the Lauswiesen field site. J. Contam. Hydrol. 88, 92-118, doi:10.1016/j.jconhyd.2006.06.005,2006.

Saavedra P., Simmer, C., and Schalge, B.: Evaluation of modeled high resolution soil moisture virtual brightness temperature compared to space-borne observations for the Neckar catchment. IEEE Xplore 14th Specialist Meeting on Microwave Radiometry and Remote Sensing of the Environment (MicroRad), pp. 85-90, doi:10.1109/MICRORAD.2016.7530510,2016.

30 Schaefer, D., Dahmke, A., Kolditz, O., and Teutsch, G.: Virtual Aquifers: A Concept for Evaluation of Exploration, Remediation and Monitoring Strategies. In: Calibration and Reliability in Groundwater Modelling: A Few Steps Closer to Reality (Proceedings of the ModelCARE 2002 Conference held in Prague, Czech Republic, June 2002), edited by K. Kovar, Z. Hrkal, IAHS Publication 277, IAHS Press Oxfordshire, pp. 52-59,2002. 
Hydrol. Earth Syst. Sci. Discuss., doi:10.5194/hess-2016-557, 2016

Manuscript under review for journal Hydrol. Earth Syst. Sci.

Published: 1 November 2016

(c) Author(s) 2016. CC-BY 3.0 License.

Schlueter, S., Vogel, H.-J., Ippisch, O., Bastian, P., Roth, K., Schelle, H., Durner, W., Kasteel, R., and Vanderborght, J.: Virtual soils: assessment of the effects of soil structure on the hydraulic behavior of cultivated soils. Vadose Zone Journal 11, doi:10.2136/vzj2011.0174,2012.

Schomburg, A., Venema, V., Lindau, R., Ament, F., and Simmer, C.: A downscaling scheme for atmospheric variables to

drive soil-vegetation-atmosphere transfer models. Tellus B, 62(4), 242-258, doi:10.1111/j.1600-0889.2010.00466.x,2010.

Schomburg, A., Venema, V., Ament, F., and Simmer, C.: Disaggregation of screen-level variables in a numerical weather prediction model with an explicit simulation of subgrid-scale land-surface heterogeneity. Meteorology and Atmospheric Physics, 116(3-4), 81-94, doi:10.1007/s00703-012-0183-y,2012.

Shi, Y., Davis, K. J., Zhang, F., Duffy, C. J., and Yu, X.: Parameter estimation of a physically based land surface hydrologic

10 model using the ensemble Kalman filter : A synthetic experiment, Water Resources Research, 50(1), 706-724, doi:10.1002/2013wr014070,2014.

Shi, Y., Davis, K. J., Zhang, F., Duffy, C. J., and Yu, X.: Parameter estimation of a physically-based land surface hydrologic model using an ensemble Kalman filter: A multivariate real-data experiment, Advances in Water Resources, 83, 421-427, doi:10.1016/j.advwatres.2015.06.009,2015.

15 Shrestha, P., Sulis,, M., Masbou, M., Kollet, S., and Simmer, C.: A scale-consistent terrestrial systems modeling platform based on COSMO, CLM, and ParFlow. Monthly Weather Review, 142(9), 3466-3483, doi:10.1175/MWR-D-14$00029.1,2014$.

Shrestha, P., Sulis, M., Simmer, C., Kollet, S.: Impacts of grid resolution on surface energy fluxes simulated with an integrated surface-groundwater flow model, Hydrol. Earth Syst. Sci., 19, 4317-4326, doi:10.5194/hess-19-4317-2015,2015.

20 Simmer, C., Thiele-Eich, I., Masbou, M., Amelung, W., Crewell, S., Diekkrueger, B., Ewert, F., Hendricks Franssen, H.-J., Huisman, A. J., Kemna, A., Klitzsch; N., Kollet, S., Langensiepen, M., Loehnert, U., Rahman, M., Rascher, U., Schneider, K., Schween, J., Shao, Y., Shrestha, P., Stiebler, M., Sulis, M., Vanderborght, J., Vereecken, H., van der Kruk, J., Zerenner, T., and Waldhoff, G.: Monitoring and Modeling the Terrestrial System from Pores to Catchments - the Transregional Collaborative Research Center on Patterns in the Soil-Vegetation-Atmosphere System. Bulletin of the American 25 Meteorological Society, 96, 1765-1787. doi:10.1175/BAMS-D-13-00134.1,2015.

Smith, V. H., Mobbs, S. D., Burton, R. R., Hobby, M., Aoshima, F., Wulfmeyer, V., and Di Girolamo, P.: The role of orography in the regeneration of convection: A case study from the convective and orographically-induced precipitation study. Meteorologische Zeitschrift, Vol. 24, No. 1, 83-97, doi:10.1127/metz/2014/0418,2015.

Sulis, M., Langensiepen, M., Shrestha, P., Schickling, A., Simmer, C., and Kollet, S. J.: Evaluating the influence of plant-

30 specific physiological parameterizations on the partitioning of land surface energy fluxes. Journal of Hydrometeorology, 16(2), 517-533, doi:10.1175/JHM-D-14-0153.1,2015.

Szintai, B., and Kaufmann, P.: TKE as a measure of turbulence. COSMO Newsletter 8, 2-9,2008.

Tian, Y., Dickinson, R. E., Zhou, L., Zeng, X., Dai, Y., Myneni, R. B., Knyazikhin, Y., Zhang, X., Friedl, M., Yu, I., Wu, W., and Shaikh, M.: Comparison of seasonal and spatial variations of leaf area index and fraction of absorbed photosynthetically 
Hydrol. Earth Syst. Sci. Discuss., doi:10.5194/hess-2016-557, 2016

Manuscript under review for journal Hydrol. Earth Syst. Sci.

Published: 1 November 2016

(c) Author(s) 2016. CC-BY 3.0 License.

(c) (1)
Hydrology and Earth System Sciences

Discussions

active radiation from Moderate Resolution Imaging Spectroradiometer (MODIS) and Common Land Model. J. Geophys. Res., 109, D01103, doi:10.1029/2003JD003777,2004.

Tietje, O., and Hennings, V.: Accuracy of the saturated hydraulic conductivity prediction by pedo-transfer functions compared to the variability within FAO textural classes. Geoderma, 69, 71-84. doi:10.1016/0016-7061(95)00050-X,1996.

5 Tóth, B., Weynants, M., Nemes, A., Makó, A., Bilas, G., and Tóth, G.: New generation of hydraulic pedotransfer functions for Europe: New hydraulic pedotransfer functions for Europe. Eur. J. Soil Sci., 66, 226-238. doi:10.1111/ejss.12192,2015. Valcke, S.: OASIS3 PRISM Model Interface Library: OASIS3 User Guide. PRIMS Support Initiative, Report No. 3,2006. Weiler, M., and McDonnell, J.: Virtual experiments: a new approach for improving process conceptualization in hillslope hydrology. Journal of Hydrology 285, 3-18. doi:10.1016/S0022-1694(03)00271-3,2004.

10 Zeng, X., Shaikh, M., Dai, Y., Dickinson, R. E., Myneni, R.: Coupling of the common land model to the NCAR community climate model. J. Climate 15, 1832-1854, doi:10.1175/1520-0442(2002)015<1832:COTCLM>2.0.CO;2,2002.

Zimmerman, D. A., G. de Marsily, G., C.A. Gotway, C. A., M.G. Marietta, M. G., C.L. Axness, C. L., R.L. Beauheim, R. L., Bras, R. L., Carrera, J., Dagan, G., Davies, P. B., Gallegos, D. P., Galli, A., Gomez-Hernandez, J., Grindrod, P., Gutjahr, A. L., Kitanidis, P. K., Lavenue, A. M., McLaughlin, D., Neuman, S. P., RamaRao, B. S., Ravenne, C., and Rubin, Y.: A 15 comparison of seven geostatistically based inverse approaches to estimate transmissivities for modeling advective transport by groundwater flow, Water Resour Res 34(6), 1373-1413, doi:10.1029/98WR00003,1998. 
Hydrol. Earth Syst. Sci. Discuss., doi:10.5194/hess-2016-557, 2016

Manuscript under review for journal Hydrol. Earth Syst. Sci.

Published: 1 November 2016

\section{A: Germany}



Figure 1: Location of the Neckar catchment within SW Germany. 


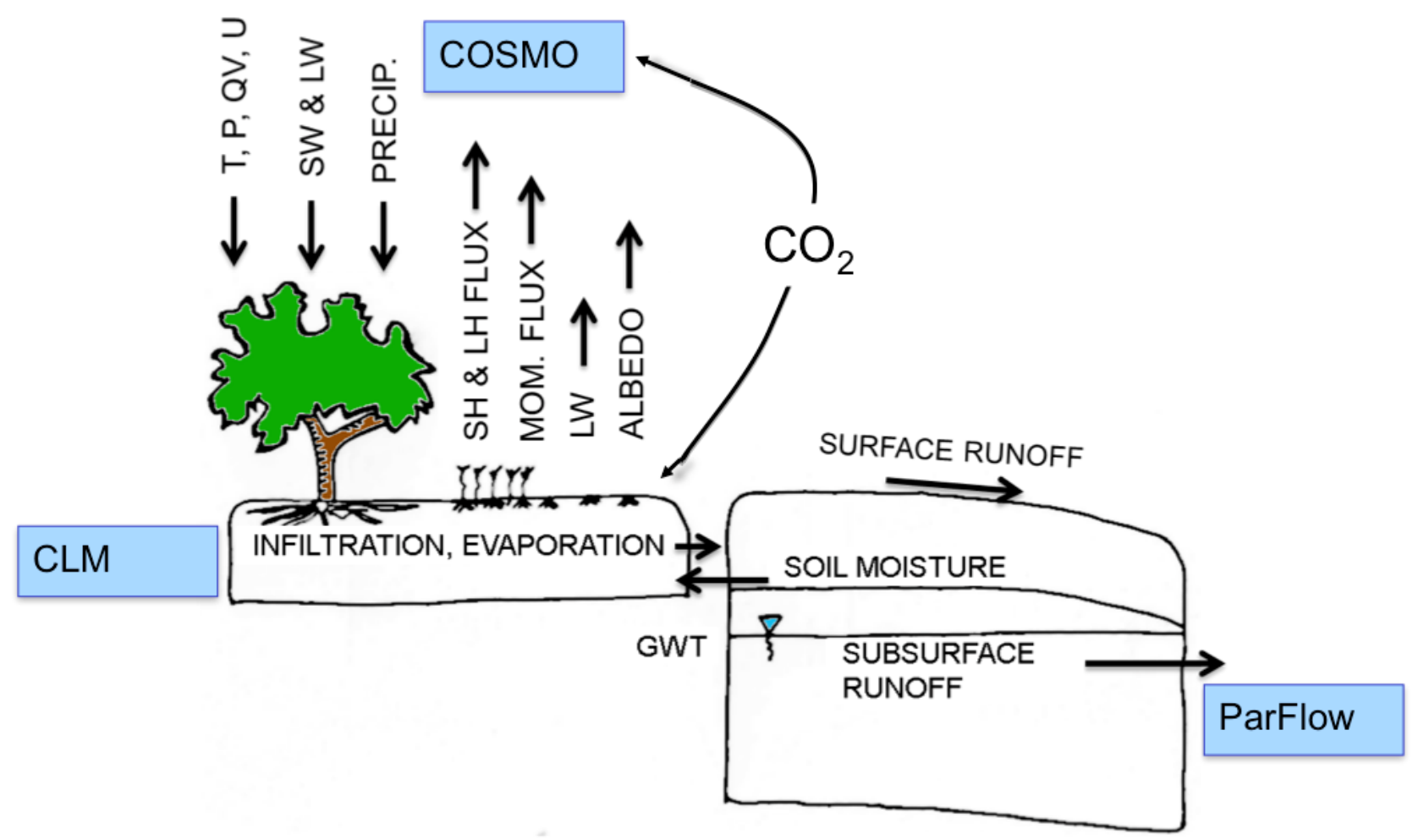

Figure 2: Exchange of energy and mass fluxes in TerrSysMP (Gasper et al., 2014). 
Hydrol. Earth Syst. Sci. Discuss., doi:10.5194/hess-2016-557, 2016 Manuscript under review for journal Hydrol. Earth Syst. Sci.

Published: 1 November 2016

(c) Author(s) 2016. CC-BY 3.0 License.

\section{Hydrology and Earth System Sciences \\ Discussions}

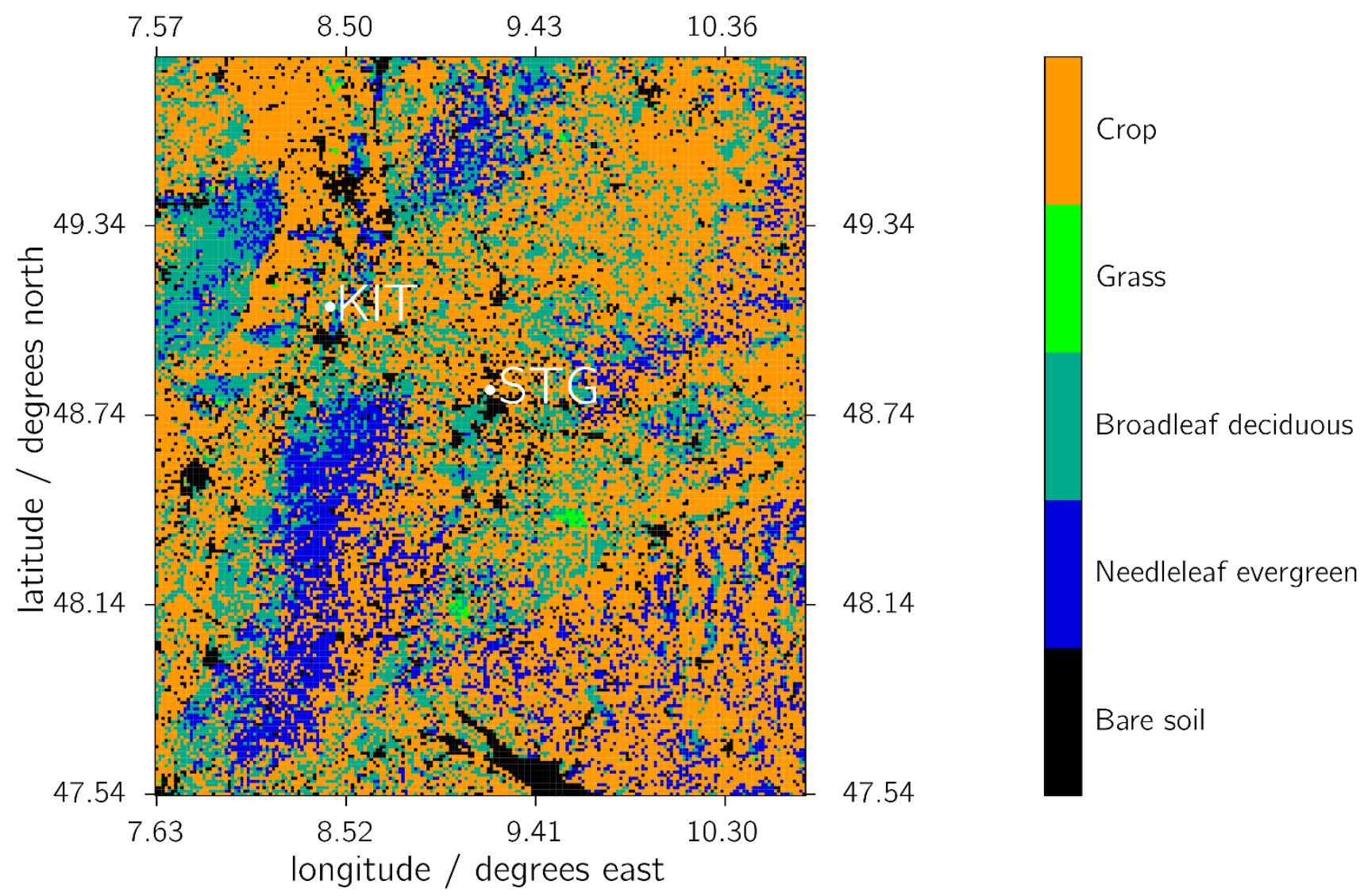

Figure 3: Land cover in Domain 1 covering the entire Neckar catchment and bounding areas. KIT: Karlsruhe Institute of Technology (location of meteorological tower observations), STG: Stuttgart (location of radiosonde observations). 
Hydrol. Earth Syst. Sci. Discuss., doi:10.5194/hess-2016-557, 2016

Manuscript under review for journal Hydrol. Earth Syst. Sci.

Published: 1 November 2016

(c) Author(s) 2016. CC-BY 3.0 License.

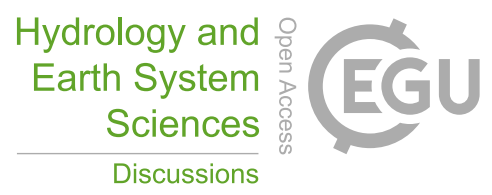

(c) ${ }_{\mathrm{By}}$

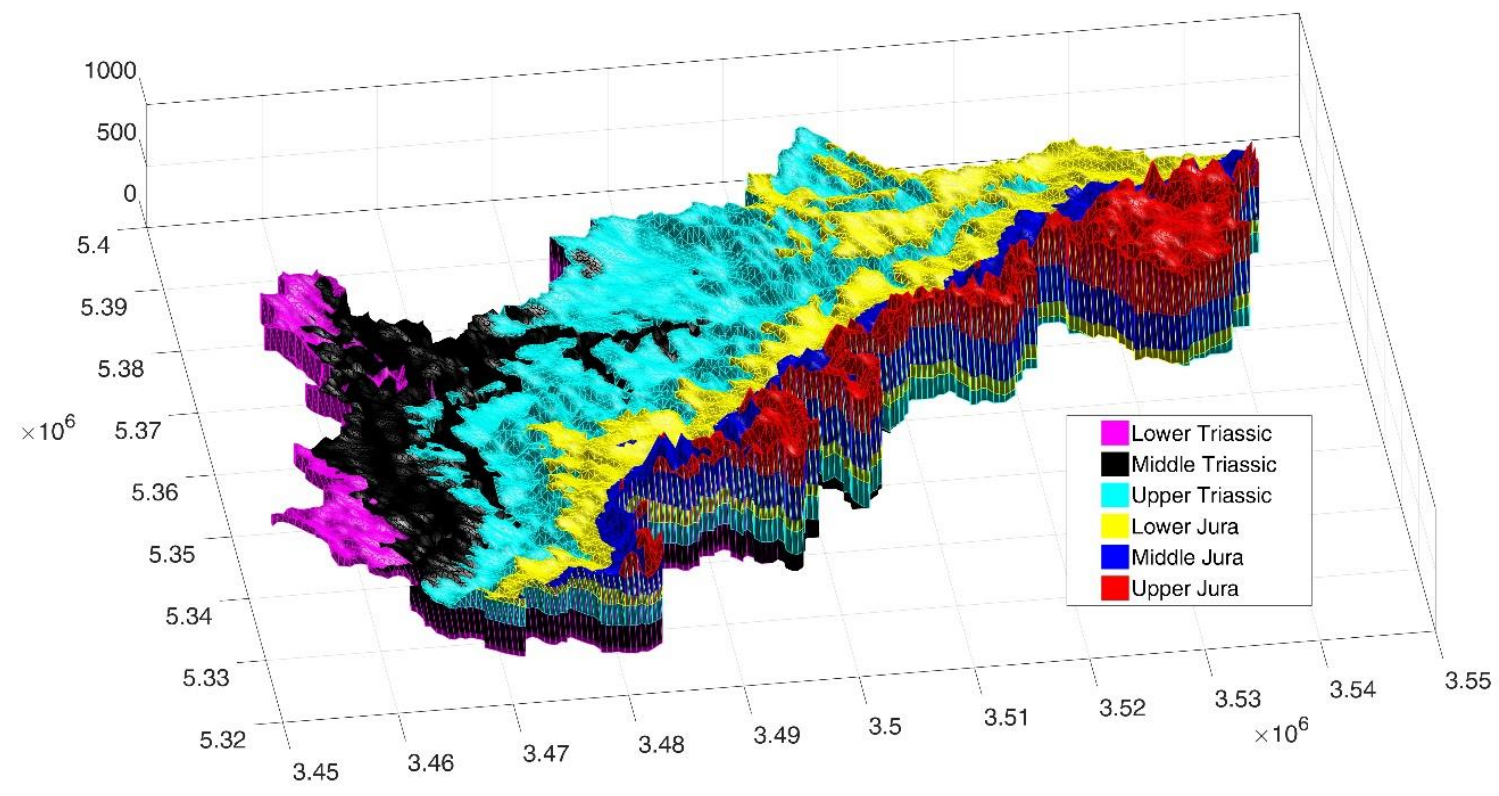

Figure 4: Stratigraphy in Domain 2 (Upper Neckar Catchment) shown in UTM-coordinates [m]. A larger version of the same dataset is used in Domain 1. 
Hydrol. Earth Syst. Sci. Discuss., doi:10.5194/hess-2016-557, 2016

Manuscript under review for journal Hydrol. Earth Syst. Sci.

Published: 1 November 2016

Hydrology and

(c) Author(s) 2016. CC-BY 3.0 License.

(c) (i)
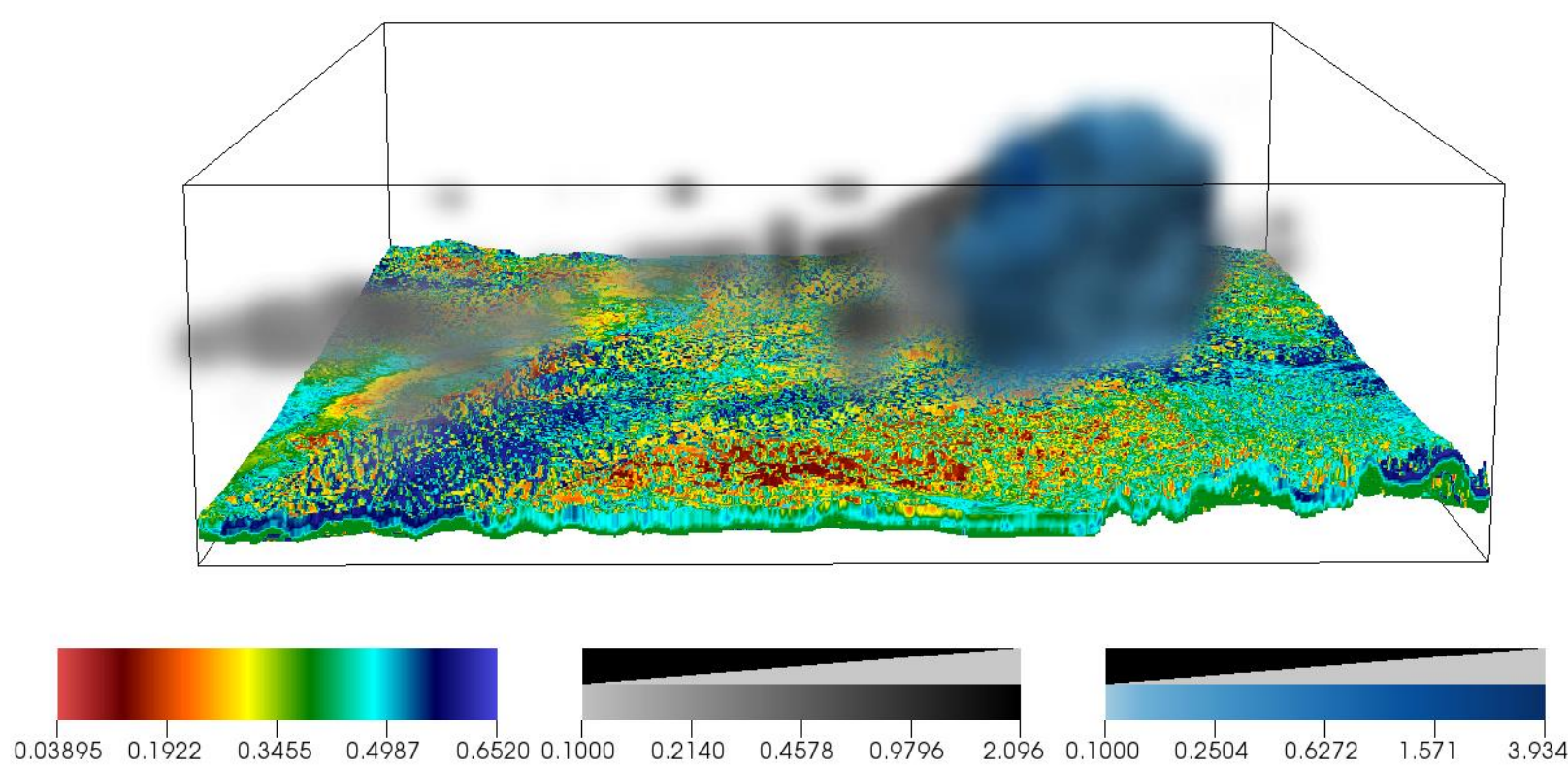

Figure 5: Snapshot of the three dimensional distribution of cloud water/ice $[\mathrm{g} / \mathrm{kg}$ ] (greyscale), precipitation/rain water [g/kg] (blue in foreground over cloud) and soil moisture $[\mathrm{cm} 3 / \mathrm{cm} 3]$ (colored) at a time point with a single rain cloud with light rain. 
Hydrol. Earth Syst. Sci. Discuss., doi:10.5194/hess-2016-557, 2016

Manuscript under review for journal Hydrol. Earth Syst. Sci.

Published: 1 November 2016

(c) Author(s) 2016. CC-BY 3.0 License.
Hydrology and

Earth System

Sciences

Discussions

(c) (i)


Figure 6: Monthly average evapotranspiration (ET) of the upper Neckar catchment simulated for Domain 2 for March and April 2007 in $[\mathrm{mm} / \mathrm{day}]$. 
Hydrol. Earth Syst. Sci. Discuss., doi:10.5194/hess-2016-557, 2016

Manuscript under review for journal Hydrol. Earth Syst. Sci.

Published: 1 November 2016

(c) Author(s) 2016. CC-BY 3.0 License.
Hydrology and

Earth System

Sciences

Discussions

(c) (1)
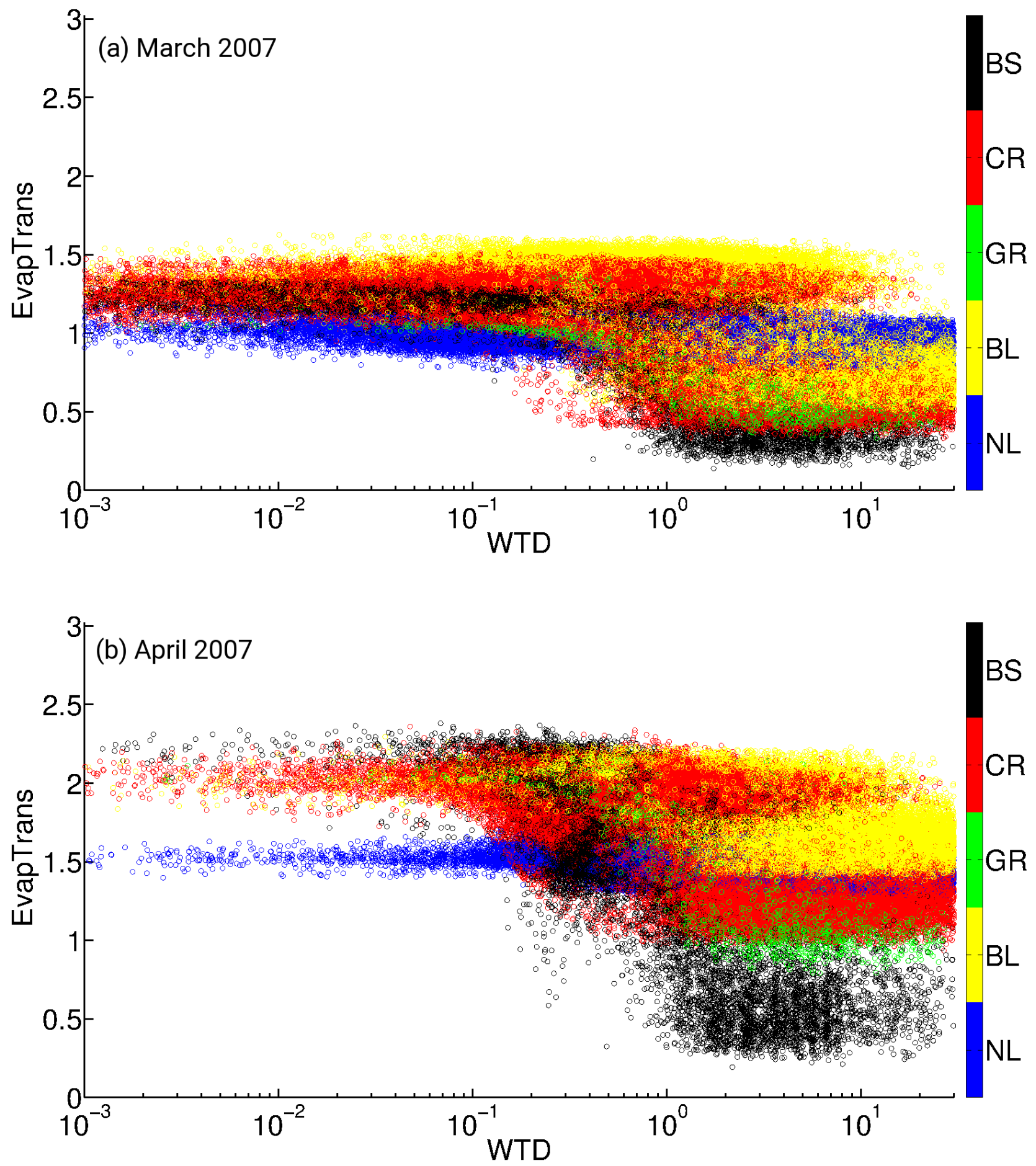

Figure 7: Evapotranspiration (ET [mm/day]) as a function of distance to groundwater (water-table depth - WTD [m]). Color code indicates land use class of the respective cell with $\mathrm{NL}=$ needle-leaf forest, $\mathrm{BL}=$ broadleaf-forest, $\mathrm{GR}=\mathrm{grassland}, \mathrm{CR}=\mathrm{agricultural}$ land and BS=bare soil. Shown are the months March (top) and April(bottom). 
Hydrol. Earth Syst. Sci. Discuss., doi:10.5194/hess-2016-557, 2016

Manuscript under review for journal Hydrol. Earth Syst. Sci.

Published: 1 November 2016

(c) Author(s) 2016. CC-BY 3.0 License.
Hydrology and

(c) $\underset{\mathrm{BY}}{(i)}$

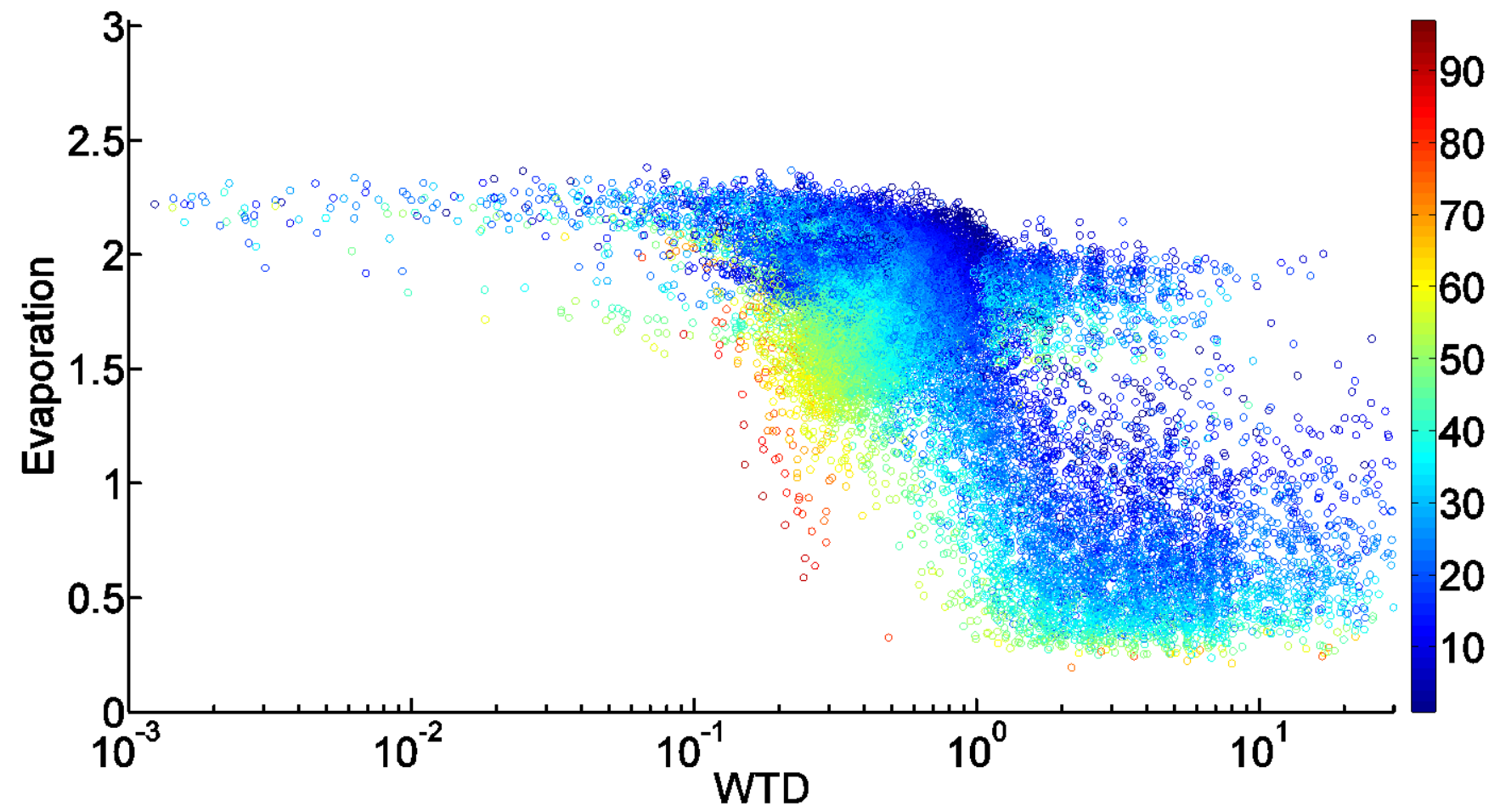

Figure 8: Evapotranspiration (ET [mm/day]) as a function of distance to groundwater (water-table depth - WTD [m]). For bare-soil cells only, color code indicates soil sand percentage. Results are from April 2007. 
Hydrol. Earth Syst. Sci. Discuss., doi:10.5194/hess-2016-557, 2016

Manuscript under review for journal Hydrol. Earth Syst. Sci.

Published: 1 November 2016

(c) Author(s) 2016. CC-BY 3.0 License.
Hydrology and

Earth System

Sciences

Discussions

(c) (1)
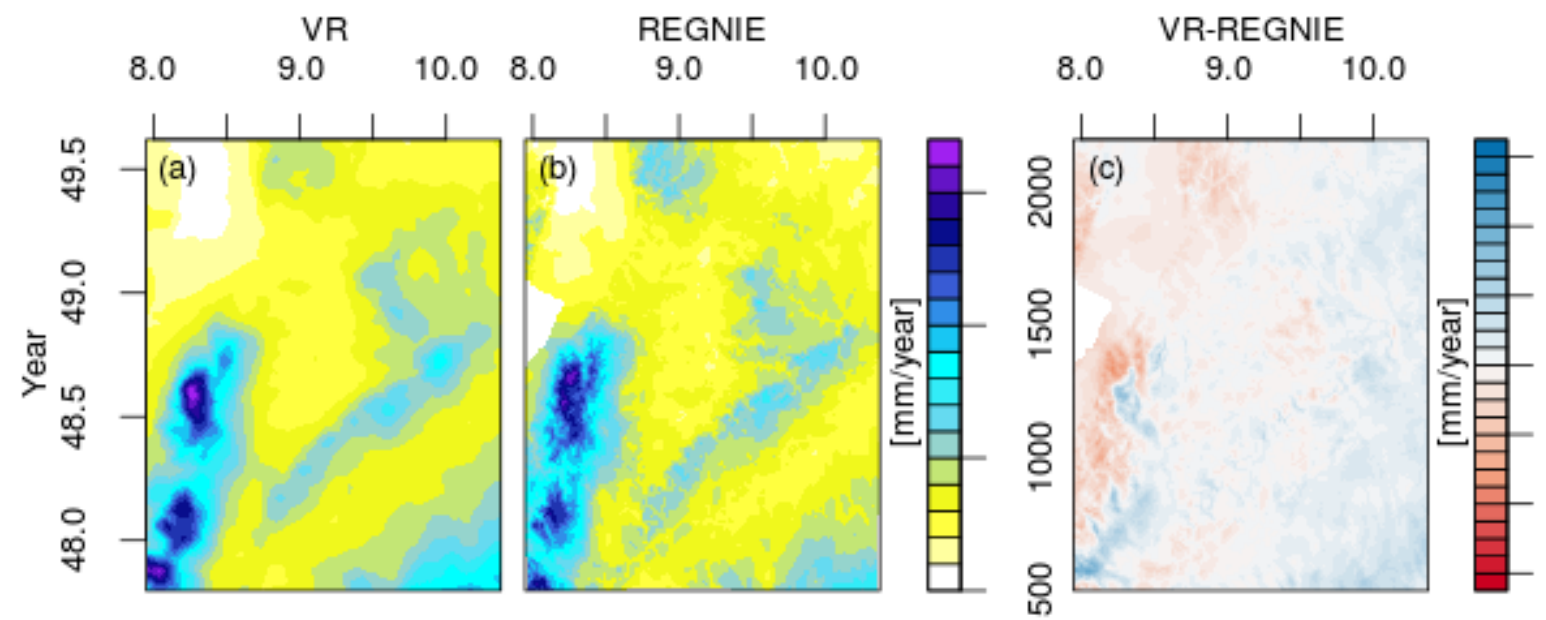

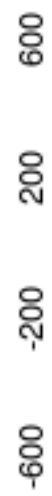
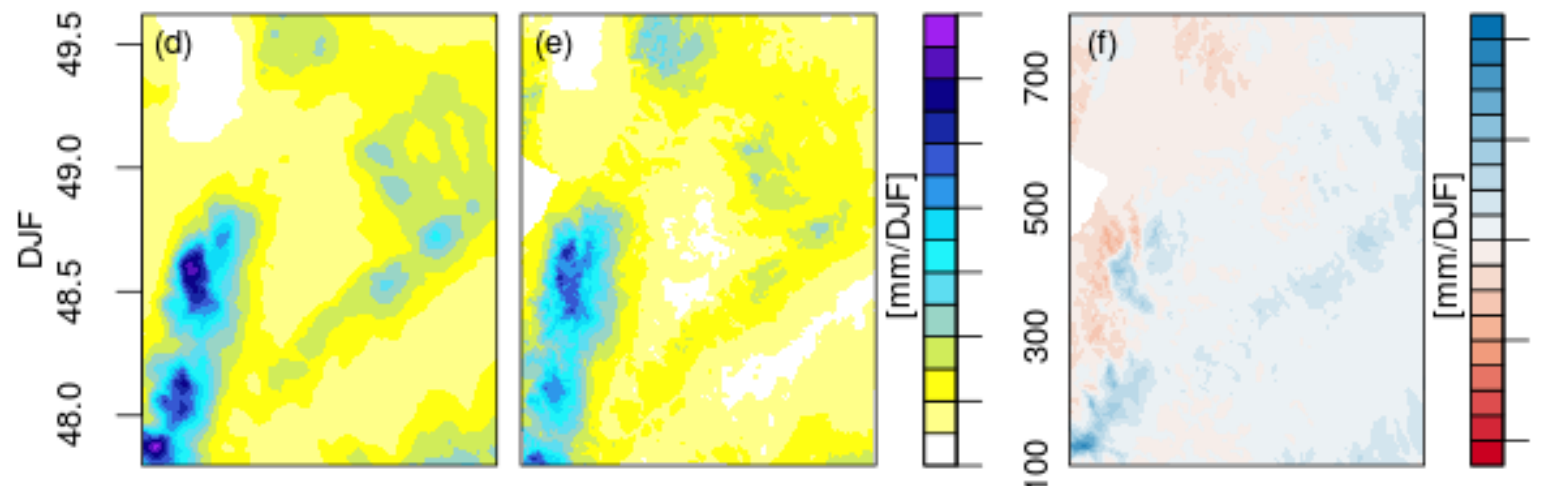

용
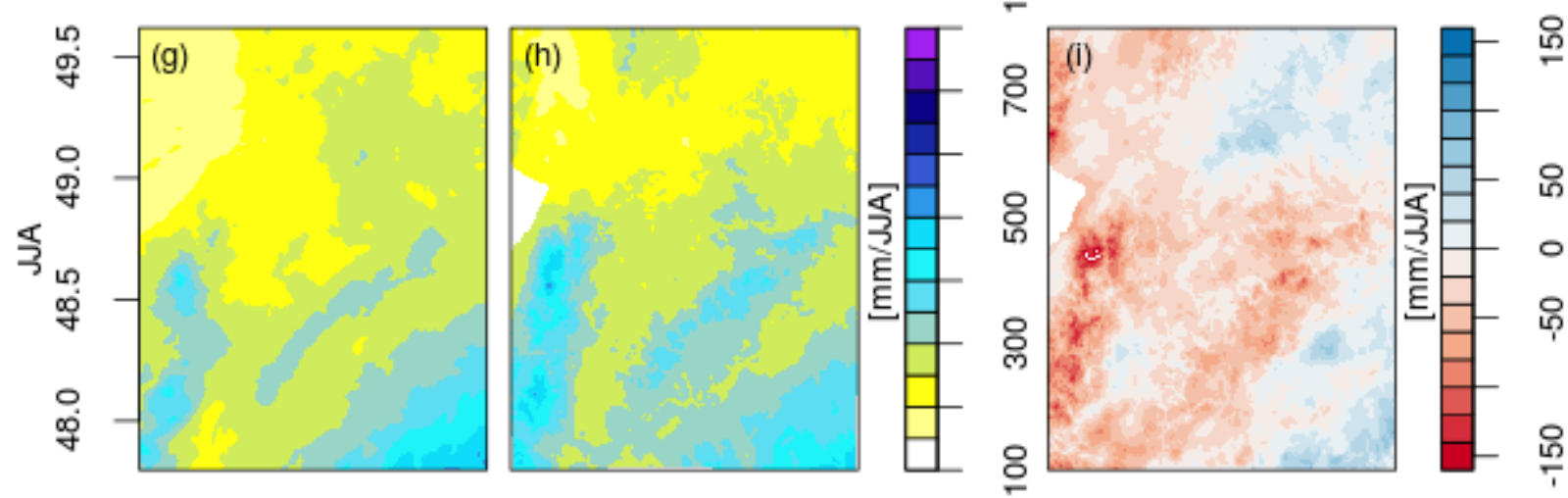

Figure 9: Mean annual precipitation over the Neckar catchment between 2007-2013 in the virtual reality (a) and the REGNIE data set (b). The difference between virtual reality and REGNIE is shown in (c). Figure (d), (e), and (f) show the comparison for the winter season (December-February) and (g), (h), and (i) for the summer season (June-August). 
Hydrol. Earth Syst. Sci. Discuss., doi:10.5194/hess-2016-557, 2016

Manuscript under review for journal Hydrol. Earth Syst. Sci.

Published: 1 November 2016

(c) Author(s) 2016. CC-BY 3.0 License.
Hydrology and

Earth System

Sciences

Discussions

(a) Summer

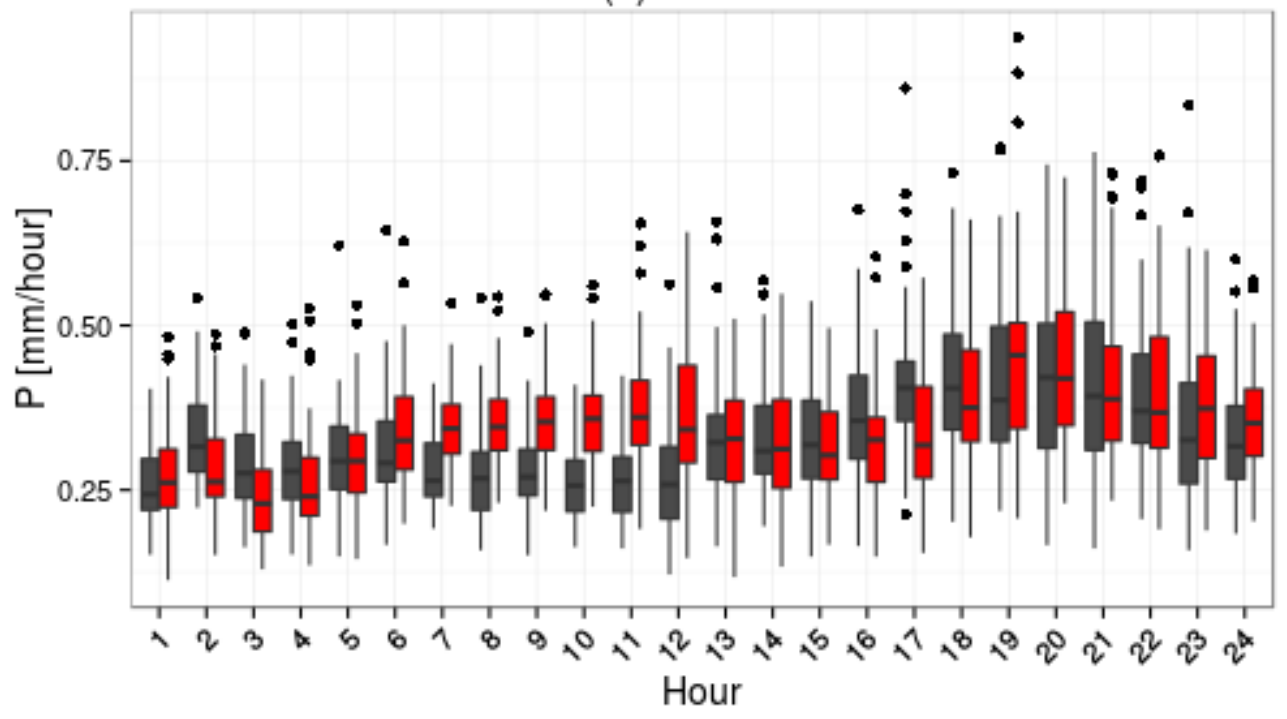

(b) Winter
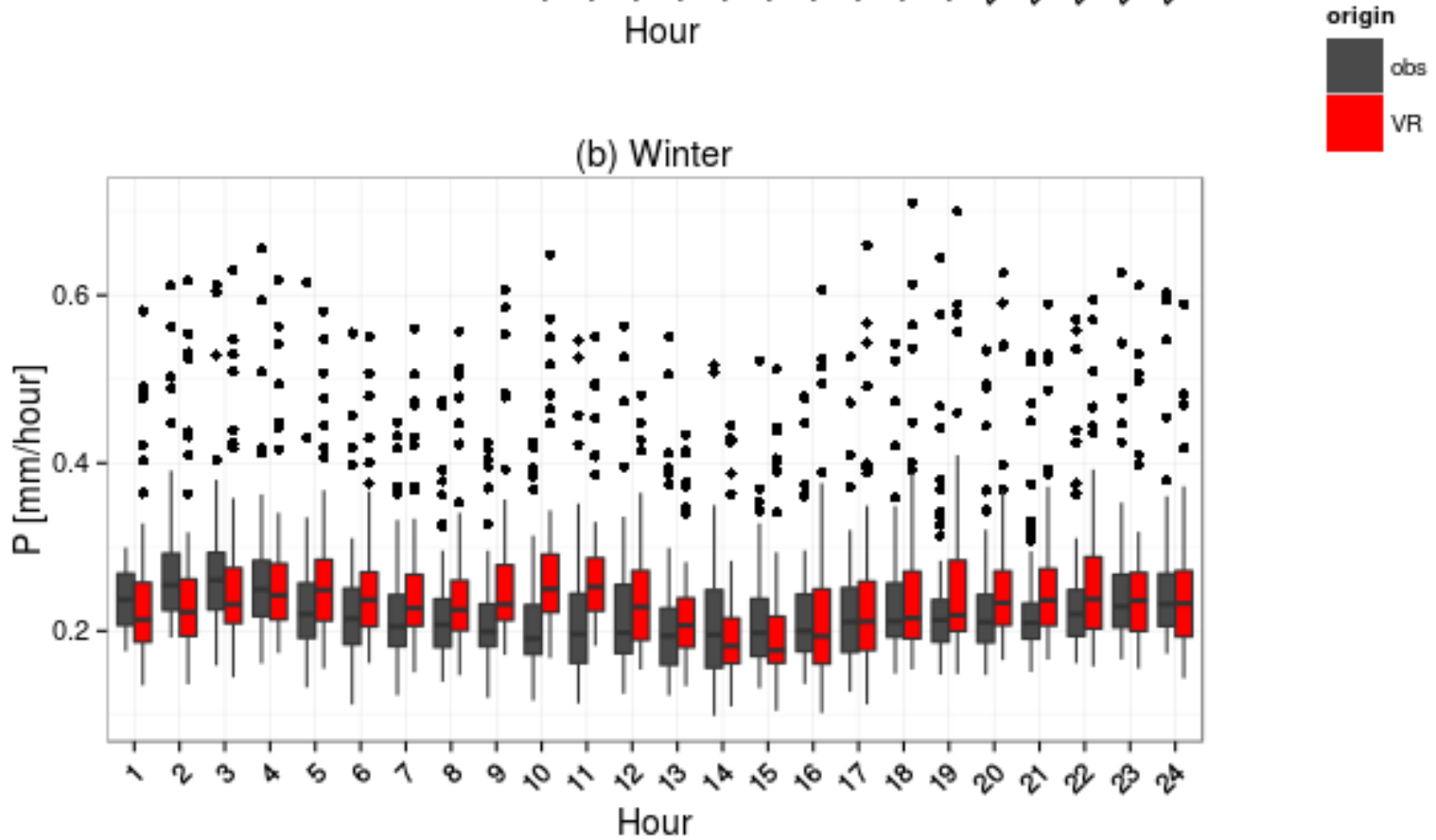

Figure 10: Mean diurnal precipitation cycle for the stations displayed in Figure A 1 and the corresponding simulations for wet days (more than 1 [mm/day]) for June-August (a) and December-February (b) season. The upper and lower hinges correspond to the first and third quartile, the center black line the median, the upper whisker (analog for lower whisker) extends from the hinge to the highest value within $1.5 *$ (interquantile range), and the black dots mark the outliers. 
Hydrol. Earth Syst. Sci. Discuss., doi:10.5194/hess-2016-557, 2016

Manuscript under review for journal Hydrol. Earth Syst. Sci.

Published: 1 November 2016

(c) Author(s) 2016. CC-BY 3.0 License.
Hydrology and

Earth System

Sciences

Discussions

(a) Mean

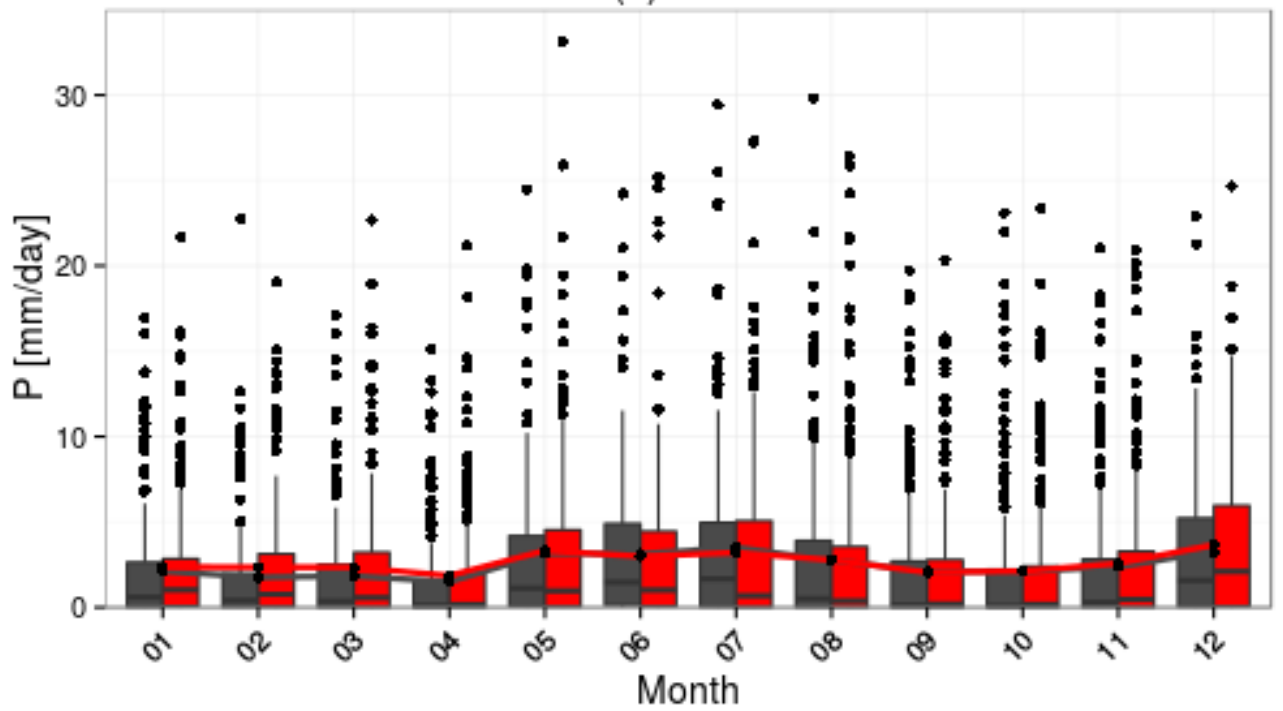

(b) Maximum

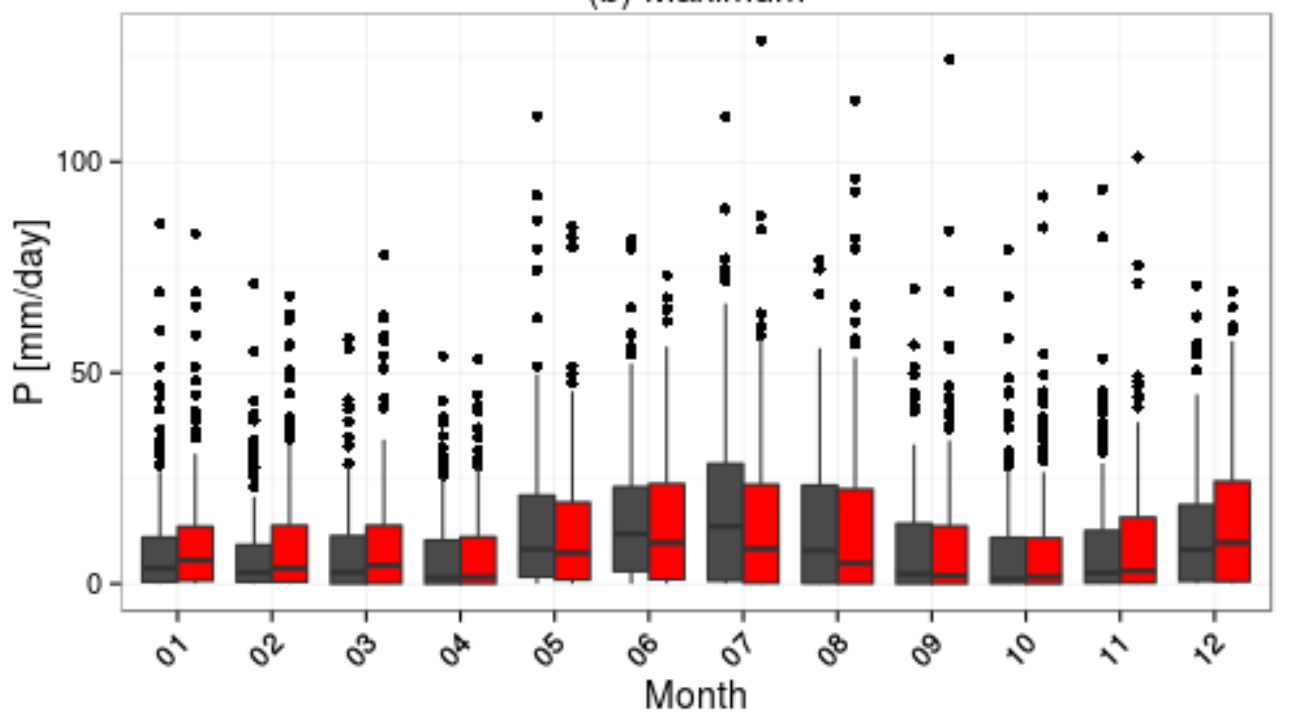

Figure 11: (a) Daily precipitation distribution on a monthly basis as observed (black) and simulated (red). The gray and red lines indicate the monthly mean precipitation. (b) Maximum daily precipitation for the given months for the stations displayed in Figure A 1. Box sizes as explained in the caption of Figure 10. 
Hydrol. Earth Syst. Sci. Discuss., doi:10.5194/hess-2016-557, 2016

Manuscript under review for journal Hydrol. Earth Syst. Sci.

Published: 1 November 2016
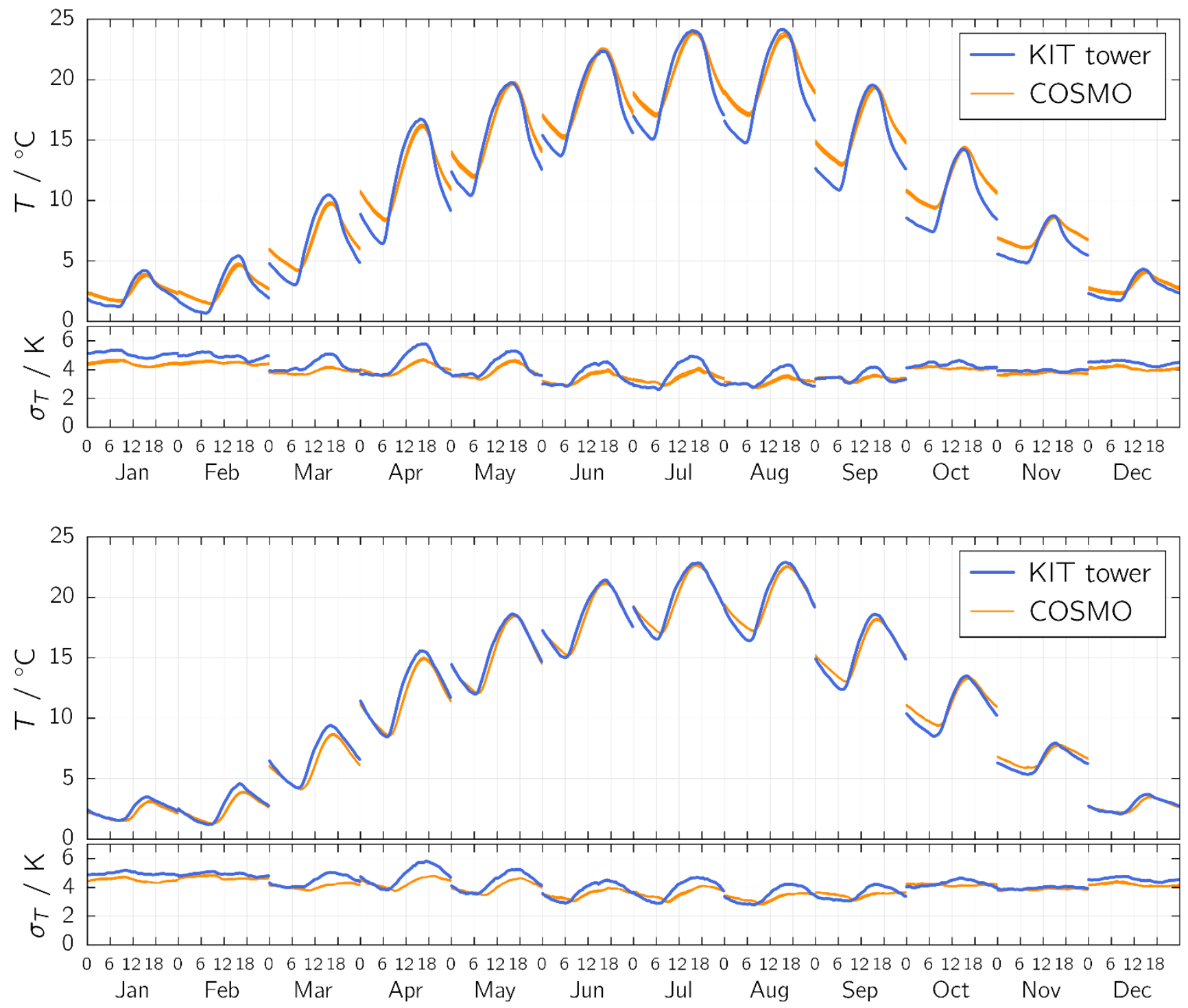

Figure 12: Monthly mean diurnal cycles (local time) and respective standard deviation for air temperature in $10 \mathrm{~m}$ (top) and $100 \mathrm{~m}$ (bottom) height at the KIT tower and for the COSMO grid boxes around the KIT location. 
Hydrol. Earth Syst. Sci. Discuss., doi:10.5194/hess-2016-557, 2016

Manuscript under review for journal Hydrol. Earth Syst. Sci.

Published: 1 November 2016

(c) Author(s) 2016. CC-BY 3.0 License.

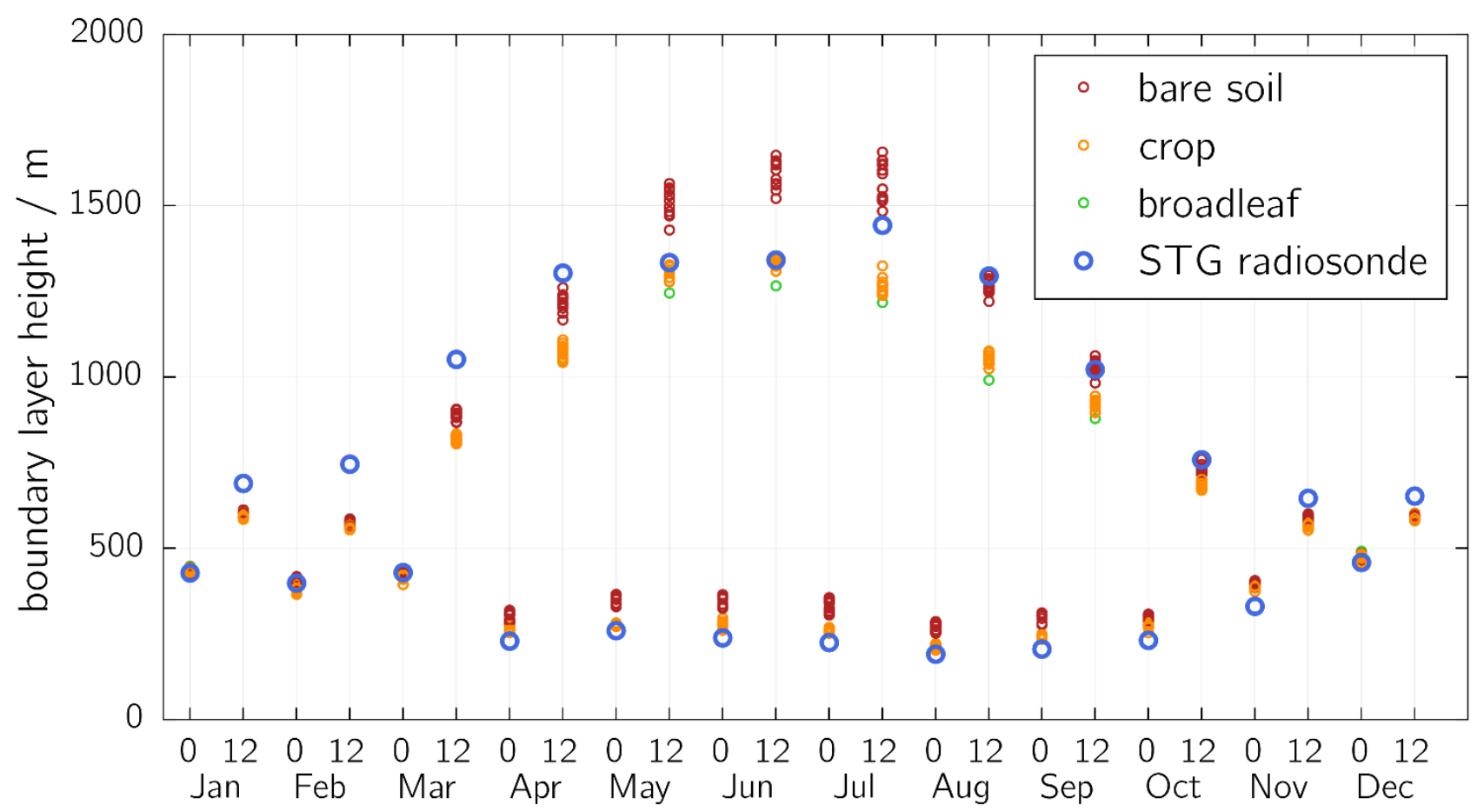

Figure 13: Monthly mean boundary layer height at $0 \mathrm{~h}$ and $12 \mathrm{~h}$ local time for different land covers diagnosed from radiosonde observations at Stuttgart STG and from atmospheric profiles above grid boxes of the virtual reality. 
Hydrol. Earth Syst. Sci. Discuss., doi:10.5194/hess-2016-557, 2016

Manuscript under review for journal Hydrol. Earth Syst. Sci.

Published: 1 November 2016

(c) Author(s) 2016. CC-BY 3.0 License.

\section{(c) (1)}

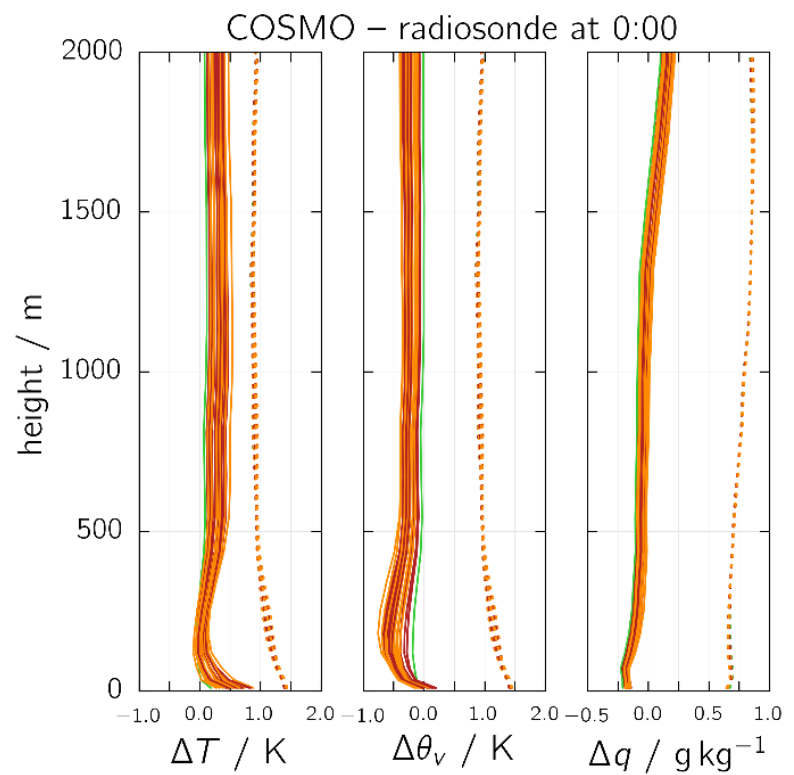

Hydrology and

Earth System

Sciences

Discussions
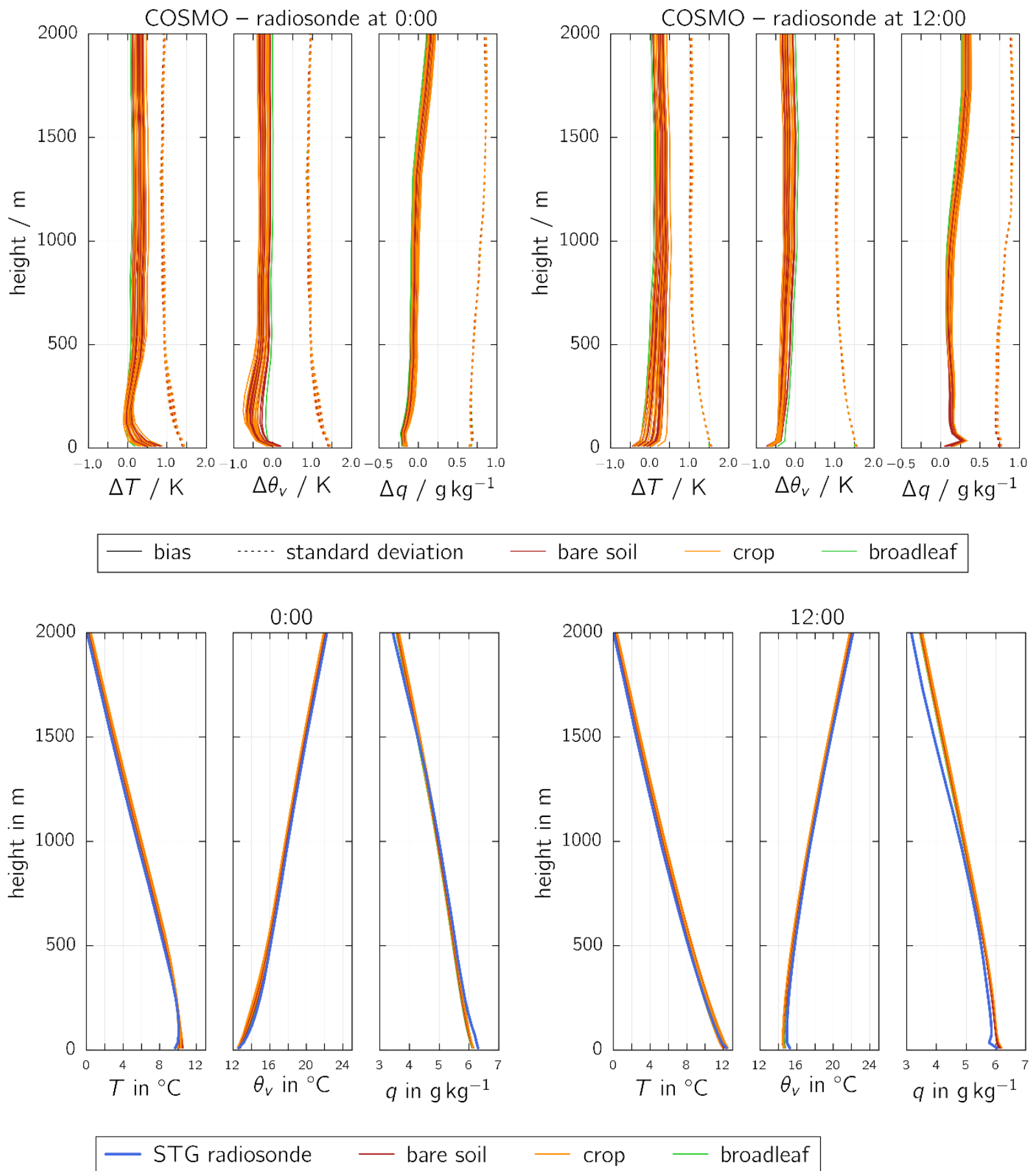

Figure 14: Mean vertical profiles of temperature, virtual potential temperature, and specific humidity (top), and mean differences between modelled and observed data including the standard deviation of the differences (bottom). The experimental data are from 5 the radiosonde data at STG and the simulated data from the grid boxes of the virtual reality with different land cover (left: $0 \mathrm{~h}$ local time, right: $12 \mathrm{~h}$ local time). 
Hydrol. Earth Syst. Sci. Discuss., doi:10.5194/hess-2016-557, 2016

Manuscript under review for journal Hydrol. Earth Syst. Sci.

Published: 1 November 2016

(c) Author(s) 2016. CC-BY 3.0 License.
Hydrology and

Earth System

Sciences

Discussions

(c) $\underset{\mathrm{BY}}{(i)}$

(a) VR D4 $\mathrm{TB}_{\mathrm{H}}[\mathrm{K}]$

(b) EASE-grid $\mathrm{TB}_{\mathrm{H}}[\mathrm{K}]$

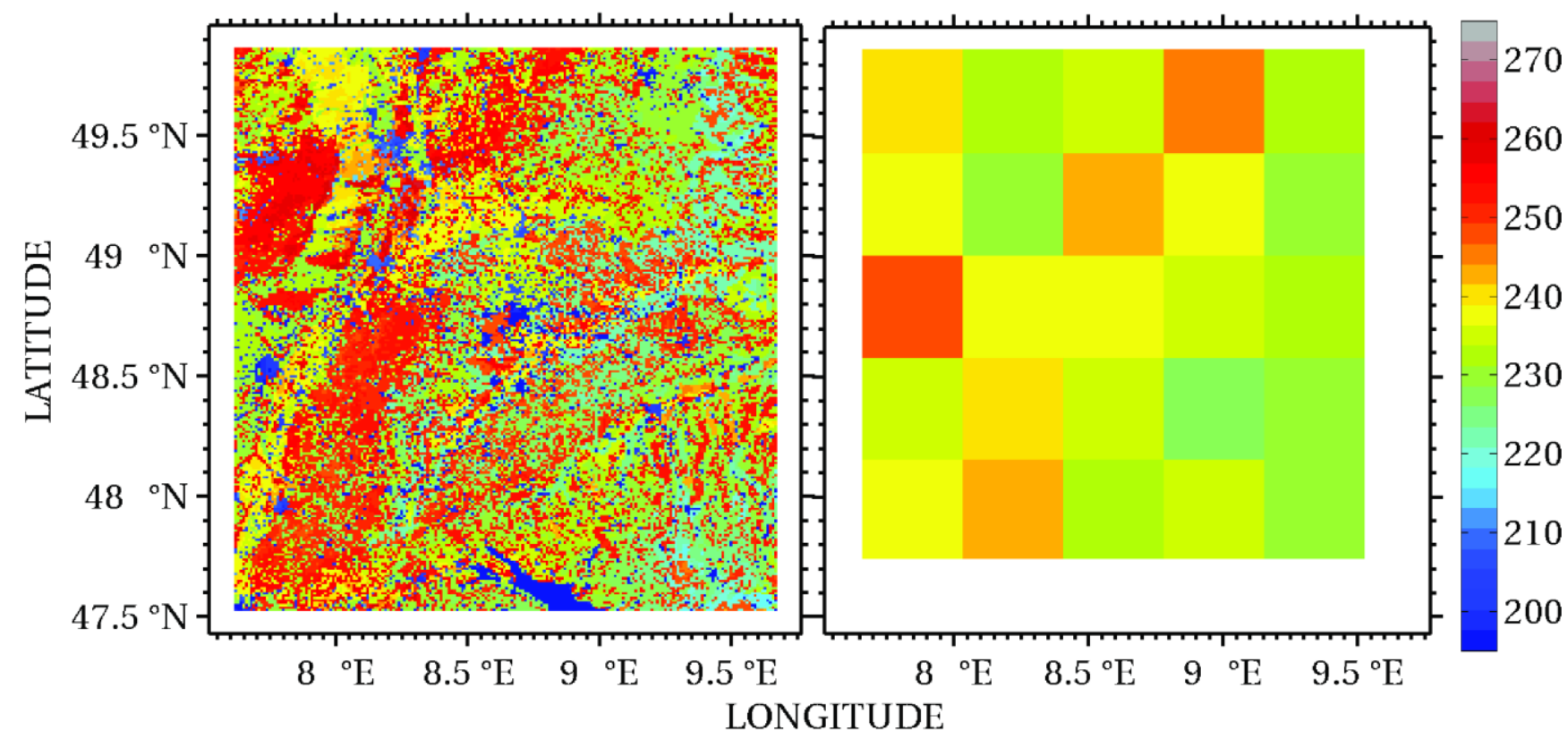

Figure 15: Brightness temperature calculated by the application of CMEM (H-polarization) on the virtual-reality output of Domain 1 on July 2nd 2011 (left) and its aggregation on the EASE grid corresponding to the spatial resolution of the SMAP passive microwave radiometer (right). 
Hydrol. Earth Syst. Sci. Discuss., doi:10.5194/hess-2016-557, 2016

Manuscript under review for journal Hydrol. Earth Syst. Sci.

Published: 1 November 2016

(c) Author(s) 2016. CC-BY 3.0 License.
Hydrology and

Earth System

Sciences

Discussions

(C) (1)
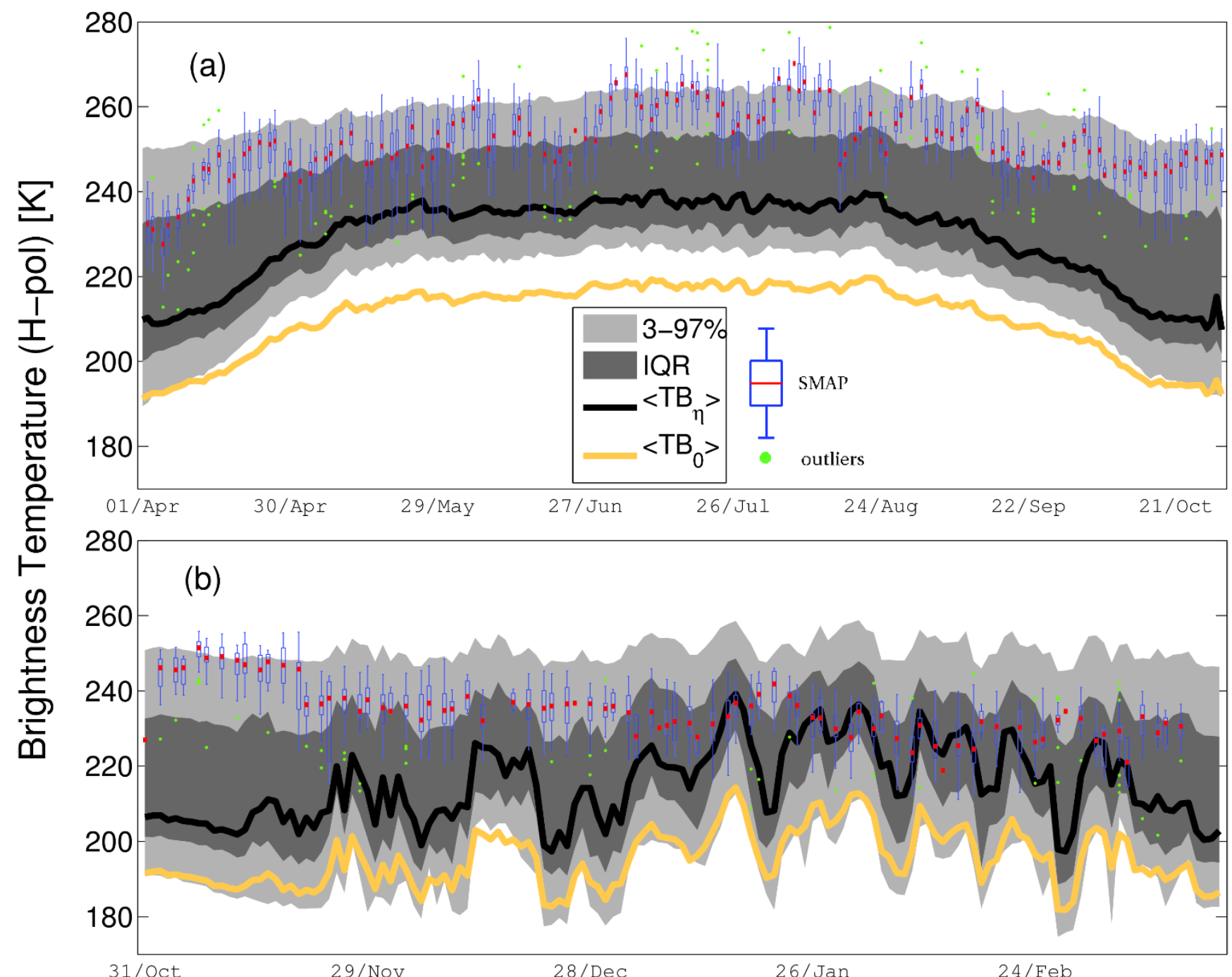

Figure 16: L-band brightness temperature for the period from April to October 2015 (top) and November to March 2015-2016 (bottom), average over the Domain 1 of the virtual reality. The boxplots indicate the SMAP observations averaged over Domain 1. The black line is the median of the virtual observations simulated with CMEM. The dark-gray area corresponds to the inter-quartile

5 range (IQR) while the light-gray area encompasses the 3 to $97 \%$ range. The orange continuous line indicates the brightness temperature without taking into account an assumed bias in surface soil moisture content (see text). 
Hydrol. Earth Syst. Sci. Discuss., doi:10.5194/hess-2016-557, 2016

Manuscript under review for journal Hydrol. Earth Syst. Sci.

Published: 1 November 2016

(c) Author(s) 2016. CC-BY 3.0 License.



Figure 17: Hourly values river discharge at the gauging station Kirchentellinsfurt for the year 2007. Blue: observed; red: simulated by the virtual reality. 
Hydrol. Earth Syst. Sci. Discuss., doi:10.5194/hess-2016-557, 2016

Manuscript under review for journal Hydrol. Earth Syst. Sci.

Published: 1 November 2016

(c) Author(s) 2016. CC-BY 3.0 License.

(c) (1)

\section{Flow Duration Curve}

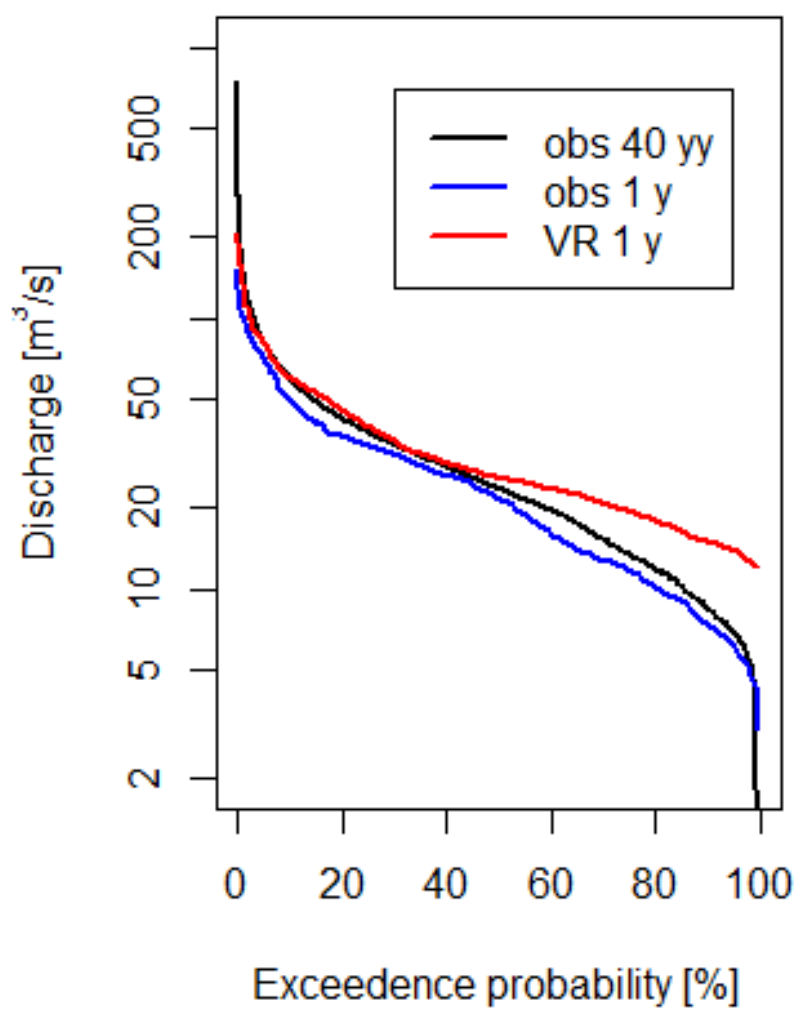

Run off coefficient



Month

Figure 18: Flow duration curve (left) and monthly runoff coefficients (right) for the year 2007 based on. Blue: observations; red: simulated by the virtual reality. In the left sub-plot also the flow duration curve for the period 1966 to 2006 is shown (black). 
Hydrol. Earth Syst. Sci. Discuss., doi:10.5194/hess-2016-557, 2016

Manuscript under review for journal Hydrol. Earth Syst. Sci.

(c) Author(s) 2016. CC-BY 3.0 License.

\section{(c) (1)}

\section{Appendix}

\section{Appendix Tables}

Table A1: Values of porosity and hydraulic conductivity of rocks found in Baden-Wuerttemberg

\begin{tabular}{|l|l|l|l|}
\hline Nr. & rock type & Ksat $[\mathrm{m} / \mathrm{h}]$ & porosity fraction \\
\hline 1 & Quarternary & 0.00100 & 0.3 \\
\hline 2 & Tertiary & 0.00100 & 0.3 \\
\hline 3 & Upper Jura & 0.00720 & 0.3 \\
\hline 4 & Middle Jura & $10^{-7}$ & 0.3 \\
\hline 5 & Lower Jura & $10^{-7}$ & 0.3 \\
\hline 6 & Upper Triassic (Keuper) & 0.00036 & 0.3 \\
\hline 7 & Middle Triassic (Muschelkalk) & 0.00180 & 0.3 \\
\hline 8 & Lower Triassic (Buntsandstein) & 0.02160 & 0.4 \\
\hline 9 & Upper Permian (Rotliegendes) & 0.00360 & 0.3 \\
\hline 10 & New Red Conglomerate & 0.00100 & 0.3 \\
\hline 11 & Bedrock/Granite & $10^{-7}$ & 0.3 \\
\hline
\end{tabular}


Hydrol. Earth Syst. Sci. Discuss., doi:10.5194/hess-2016-557, 2016

Manuscript under review for journal Hydrol. Earth Syst. Sci.

Published: 1 November 2016

(c) Author(s) 2016. CC-BY 3.0 License.

(c) (1)
Hydrology and

Discussions

Table A2: Observed atmospheric variables at KIT and STG. Local time at STG is UTC+01.




Hydrol. Earth Syst. Sci. Discuss., doi:10.5194/hess-2016-557, 2016

Manuscript under review for journal Hydrol. Earth Syst. Sci.

Published: 1 November 2016

(c) Author(s) 2016. CC-BY 3.0 License.

\section{Hydrology and \\ Earth System \\ Sciences \\ Discussions}

(c) (i)

\section{Appendix Figures}

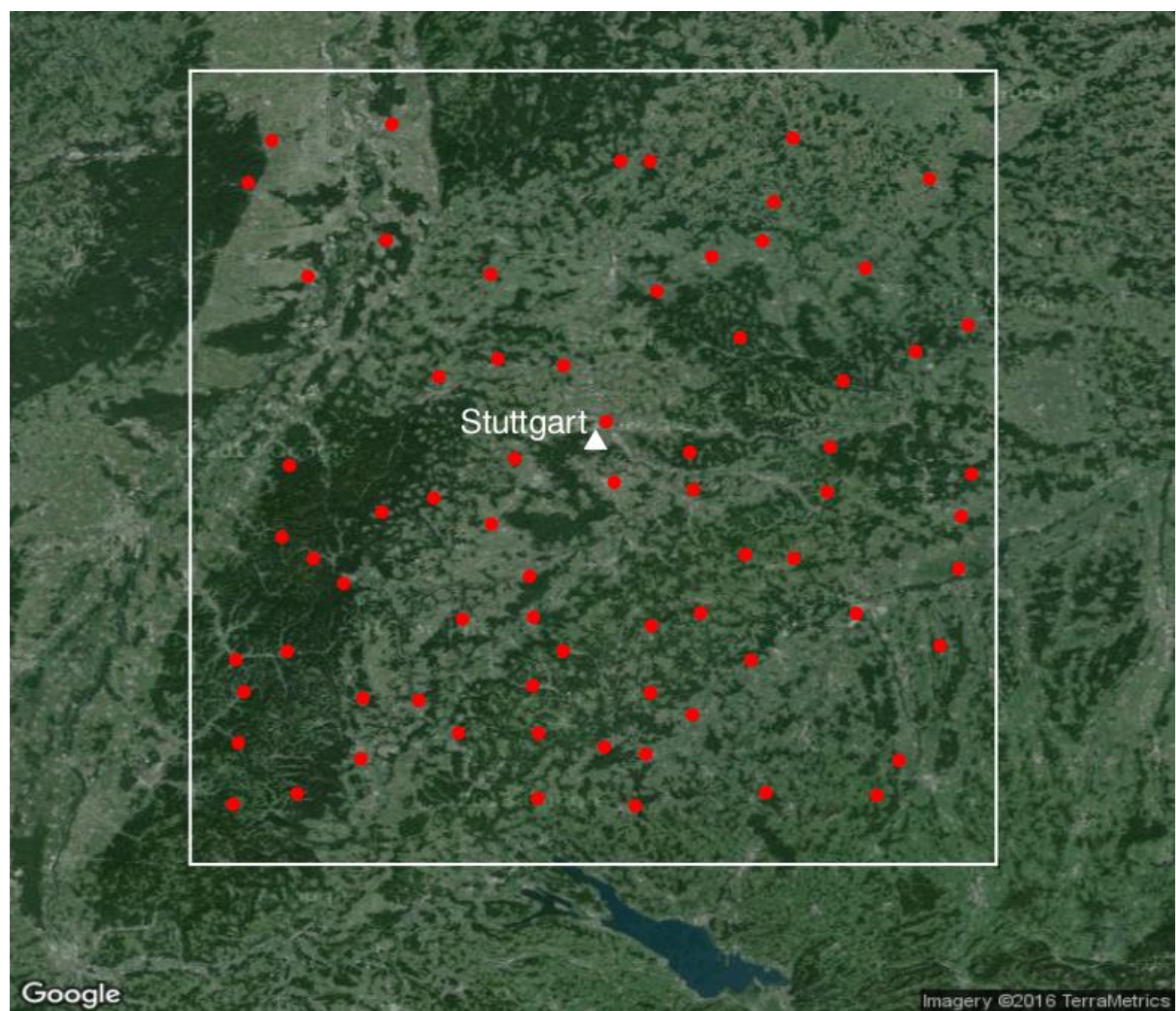

Figure A 1 Study area, the Neckar catchment, (white box) for precipitation analysis. Red dots: stations of the German Weather Service (DWD) used for time series analysis. 